Revista lus et Praxis, Año 25, No 1, 2019, pp. 251 - 284

ISSN 0717 - 2877

Universidad de Talca - Facultad de Ciencias Jurídicas y Sociales

Estudio sobre la actio utilis referida en D. 17,1,40

(Paul. 9 ed.): su alcance en el Código Civil de Bello

Juan Carlos Prado Rodríguez

Trabajo recibido el 31 de julio de 2017 y aprobado el 6 de noviembre de 2018

\title{
Estudio sobre la actio utilis referida en D. 17,1,40 (Paul. 9 ed.): su alcance en el Código Civil de Bello StUdy ABOUt THE ACTIO UTILIS REFERRED IN D. 17,1,40 (Paul. 9 ed.): ITS SCOPE IN The Civil Code Of Bello
}

Juan Carlos Prado Rodríguez

\section{RESUMEN}

El presente estudio analiza los fundamentos romanistas de la contradicción existente entre los artículos 1574 y 2291 del Código Civil chileno sobre el derecho de regreso consiguiente al pago del tercero prohibente debitore. Para ello, se estudia un texto de Paulo en D. 17,1,40 que está a la base de dicha controversia, al excluir el derecho de regreso en favor del solvens inclusive a través de la actio utilis, la cual, sin embargo, habría sido admitida por algunos jurisconsultos al objeto de mantener la aequitas. A este respecto, se asiste a un debate doctrinal sobre la identificación de la acción romana que habría sido adaptada en vía útil. Posteriormente, el jurista francés Robert Joseph Pothier también daría relevancia al mantenimiento de la aequitas para tal supuesto, lo que influenciaría la disposición del artículo 2291 del Código Civil elaborado por don Andrés Bello, que admite, en contradicción con el artículo 1574, el derecho de regreso en favor del solvens para evitar que el deudor principal obtenga un enriquecimiento injustificado.

\section{ABSTRACT}

This study analyzes the Romanist foundations of the contradiction existing between articles 1574 and 2291 of the Chilean Civil Code with respect to the right of restitution consequent to the payment of the third party prohibente debitore. The analysis focuses on a text written by Paulo in D. 17,1,40, which is at the center of this controversy, by excluding the right of return in favor of solvens even through the actio utilis, which, however, would have been admitted by some legal experts for the purpose of maintaining the aequitas. In this regard, there is a doctrinal debate about the identifying the Roman action that would have been adapted in useful way. Subsequently, the French jurist Robert Joseph Pothier also emphasized the importance of maintaining aequitas for such an event, which would influence the provision of article 2291 of the Civil Code prepared by Mr. Andrés Bello, which admits, in contradiction with article 1574 , the right of restitution in favor of solvens to prevent the primary debtor from obtaining an unjustified enrichment.

* Dottore di ricerca in Sistema Giuridico Romanistico e Unificazione del Diritto. Università degli Studi di Roma 'Tor Vergata'-Italia. Profesor Titular e Investigador en la Facultad de Derecho de la Universidad de Las Américas, Quito-Ecuador. juan.prado@udla.edu.ec. 


\author{
Palabras CLAVE \\ Solutio prohibente debitore, aequitas, enriquecimiento injustificado \\ KEY WORDS \\ Solutio prohibente debitore, aequitas, unjustified enrichment
}

\title{
1. Introducción
}

Al parecer, en la época romana clásica se habría presentado una disputa jurisprudencial sobre el derecho de regreso consiguiente al pago del tercero realizado prohibente debitore, en la que célebres jurisconsultos excluyeron toda acción para obtener el regreso de lo pagado. Sin embargo, otros juristas habrían considerado a la actio utilis como el instrumento procesal idóneo para actuar el derecho de regreso, según lo referido en D. 17,1,40, y en una constitución de Justiniano del año 530 d.C. colocada en CJ. 2,18(19),24, en la que el emperador bizantino también negó toda acción para el regreso.

Con respecto a la función que esta actio utilis habría desempeñado para el referido supuesto, la misma radicaría en el restablecer la aequitas entre las partes de la obligación, quebrantada a causa del enriquecimiento injustamente verificado en el deudor principal. Sin embargo, existe un debate en la doctrina romanista acerca de la identificación de la acción que habría sido adaptada en vía útil para tal supuesto, viéndose como posible instrumento procesal a la actio negotiorum gestorum, la misma que habría sido admitida también por algunos glosadores italianos.

En efecto, estos antecedentes marcarían las diferentes posturas doctrinales que se presentaron sobre la cuestión prohibente domino a lo largo del iter histórico del sistema jurídico romanista en Europa, en el que, en particular, el jurista francés Robert Joseph Pothier se pronunció en favor del mantenimiento de la referida aequitas, admitiendo el derecho de regreso para el solvens prohibente debitore y de esta forma contrastar el verificarse de un enriquecimiento injustificado.

Así, la postura adoptada por Pothier influenciaría la reglamentación del pago prohibente debitore en el Código Civil chileno elaborado por don Andrés Bello, en la que, sin embargo, se verificó una contradicción entre los artículos 1574 y 2291, que niegan y admiten, respectivamente, el derecho de regreso para el solvens prohibente debitore. En efecto, el artículo 1574 niega el derecho de regreso para el solvens, a pesar de que deja abierta la posibilidad de actuarlo, pero condicionada a la voluntad del acreedor de ceder sus acciones. Mientras que, por el contrario, el artículo 2291 hace explícita referencia a la utilidad de la gestión ajena para el interesado del negocio como fundamento del reembolso en favor del solvens, para así evitar que el deudor se enriquezca con detrimento ajeno. 
En este sentido, el presente estudio pretende evidenciar los fundamentos romanistas de la controversia existente en el Código Civil de Bello respecto al derecho de regreso consiguiente al pago prohibente debitore; para lo cual, se analizan los efectos de la romana actio utilis en dicho supuesto y la influencia que, a largo de la historia jurídica europea, tuvieron en don Andrés Bello, quien, aunque de forma ambigua, admitió el derecho de regreso en el artículo 2291 de su Código Civil.

\section{El origen de la cuestión prohibente debitore en el Derecho Romano clásico: la referencia a la actio utilis en D. 17,1,40}

D. 17,1,40 (Paul. 9 ed.):

Si pro te praesente et vetante fideiusserim, nec mandati actio nec negotiorum gestorum est: sed quidam utilem putant dari oportere: quibus non consentio, secundum quod et Pomponio videtur'.

El referido texto narra un supuesto de solutio del tercero prohibente debitore $^{2}$, en el que Paulo excluye el derecho de regreso en favor del fideiussore,

\footnotetext{
1 Así el texto en Schipani (2007), p. 288. "Si yo hubiere sido fiador por ti, estando tú presente y prohibiéndomelo, no hay ni la acción de mandato, ni la de gestión de negocios; pero opinan algunos que debe darse la útil, con los cuales no me conformo, según lo que también le parece a Pomponio", así García del Corral (1889), p. 861. Al parecer, el texto estaría interpolado en las expresiones praesente, fideiusserim, nec, utilem, según Levy y Rabel (1935), p. 292. Véase también Lenel (1889), p. 921 y LeNEL (1927), p. 101.

2 Es sabido que para el Derecho Romano no era necesario que la solutio la realice el deudor en persona, ya que también un tercero podía hacerlo, aun ignorante vel invito debitore, confróntese Solazzi (1935), pp. 41 y ss. Sin embargo, era necesario que el solvens actúe en nombre del deudor y con la intención de liberarlo (animus solvendi), confróntese POtHier (1939), pp. 331 y s.; Cruz (1962), p. 227. Sobre la solutio del tercero véase EMUNDS (2007), p. 472, quien analiza las diferentes formas de la intervención del solvens, junto a las respectivas acciones concedidas para obtener el derecho de regreso, véase al respecto FARGNOL (2008), pp. 886-896. Respecto a la solutio prohibente debitore, cabe diferenciar los significados de los términos invito y vetante-prohibente, para esclarecer el sentido de cada uno, ya que en D. 3,5,38(39), D. 46,3,23, D. 46,3,53 y J. 3,29, aparece la locución invito debitore, mientras que en D. 17,1,40 aparece vetante fideiusserim, y en CJ. 2,18(19),24, prohibente domino. Así pues, invitus indicaría una contrariedad a un acto que podría verificarse, pero que el sujeto que está por realizarlo no sabe de ella, o la intuye, pero procede igualmente antes de que se le comunique la prohibición; en este sentido, un sujeto puede pagar la deuda del deudor ausente sin saber que éste sea en el fondo contrario. Sobre los términos vetante-prohibente, estos equivalen a vetar o impedir, por consecuencia, indican una manifestación explícita de la contraria voluntad a la injerencia ajena, en el sentido de que quien está por cumplir el acto vetado es consciente de la prohibición, pero aun así lo realiza, confróntese PACCHIONI (1893), p. 670. Así, las fuentes que admiten la solutio del tercero invito debitore hacen alusión al término ignorante, lo que equivale a proceder en el ámbito de la negotiorum gestio. Con respecto a la voluntad presunta, véase Finazzı (2003), p. 551.
} 
así a través de la actio mandati contraria y de la actio negotiorum gestorum contraria ${ }^{3}$, lo cual resulta admisible, ya que la prohibición del deudor excluye cualquier encargo dado al fiador ${ }^{4}$, a más de algunos de los requisitos necesarios para configurar una negotiorum gestio, entre ellos, la absentia y la ignorantia domino ${ }^{5}$, lo cual se recaba de la frase con la que se abre el texto, "Si pro te praesente et vetante fideiusserim" ${ }^{\prime 6}$.

Asimismo, Paulo tampoco estaba de acuerdo, conforme a la opinión de Pomponio, en admitir una actio utilis para el regreso ${ }^{7}$, la cual habría sido considerada por algunos jurisconsultos según la frase en el texto, "sed quidam utilem putant dari oportere", lo que evidencia que hubo quienes estaban de acuerdo en admitir dicha acción ${ }^{8}$.

\footnotetext{
${ }^{3}$ En efecto, el derecho de regreso del fiador se basó en la relación que corría con el deudor principal; por lo que si el garante intervino por mandato del deudor, procederá con la actio mandati contraria, pero si lo hizo ignorante debitore, con la actio negotiorum gestorum contraria, presuponiendo una útil gestión para el deudor, todo ello sin que existan los factores que excluían el regreso para el solvens, como cuando la solutio se realizó animo donandi o prohibente debitore, supuesto este último en el que surge la cuestión respecto a cuál instrumento procesal conceder para el regreso, confróntese BIONDI (1972), p. 446.

${ }^{4}$ Confróntese Talamanca (1968), p. 337.

${ }^{5}$ Observa al respecto Pasquau (1986), p. 96: "El dominus, al prohibir la gestión, demuestra tener la dirección de su negocio, pudiendo proveer por sí mismo directa o indirectamente. La prohibitio domini es, obviamente, una clara manifestación de su presencia (jurídica) en el locus negotii". Véase D. $3,5,1$ y D. $3,5,3,10$.
}

${ }^{6}$ Respecto a la prohibitio manifestada sucesivamente a la solutio, observa FInAzZI (2003), p. 550, que el reconocimiento de la negotiorum gestio implicaba la imposibilidad de que el deudor pueda rechazar los efectos de una gestión útil, siendo irrelevante una prohibición sucesiva a la gestión ajena.

7 Resulta discutible que Pomponio haya excluido tal derecho, ya que es autor de dos importantes máximas en las que está a favor de mantener la aequitas entre las partes, prohibiendo que nadie se enriquezca con detrimento ajeno, así en D. 50,17,206 (10. ex variis lect.): lure naturae aequum est neminem cum alterius detrimento et iniuria fieri locupletiorem, y en D. 12,6,14 (21. ad sab.): Nam hoc natura aequum est, neminem cum alterius detrimento fieri locupletatiorem. A menos que Paulo se refiera a lo referido por Pomponio en D. 50,17,36 (17. ad sab.): Culpa est inmiscere se re ad se non pertinent. A tal respecto, observa Riccobono (1917), p. 21, como el Derecho Romano se basó en el principio de la autonomía patrimonial, lo que excluye cualquier injerencia contraria a la voluntad del dominus y en la que no se justifican aquellas intromisiones basadas solo en presunciones, por lo que la gestión será útil cuando se refiera a negocios que el interesado habría querido gestionar por sí mismo si no hubiese estado impedido. Sin embargo, para Salas (1982), p. 357, la máxima de D. 50,17,36 no es absoluta, ya que cuando los interesados de los negocios no se hallan en condición de proveer ellos mismos, el derecho permite dicha injerencia en cuanto sea útil, según se recaba del Edicto de negotis gestiis en D. 3,5,1.

${ }^{8}$ Esta frase hace que el texto resulte significativo para entender si hubo una disputa sobre la admisión del derecho de regreso consiguiente a la gestio prohibente domino en la época clásica; en efecto, en el texto aparece una de las pocas referencias sobre la posibilidad de conceder dicha actio utilis 
Esta circunstancia ha planteado la hipótesis de que para la época haya surgido un debate jurisprudencial respecto a los efectos de la gestio prohibente domino ${ }^{9}$, en el que para algunos, el gestor disponía de una actio utilis modelada mediante la adaptación de la actio negotiorum gestorum en consecuencia del quebrantamiento de la aequitas y del consiguiente enriquecimiento injustamente obtenido por el dominus negotii ${ }^{10}$; sin embargo, Paulo se manifestó contrario en admitir dicha acción, como se recaba de D. 17,1,40 ${ }^{11}$.

Sobre esta supuesta disputa, Schul ${ }^{12}$ considera que la misma no habría surgido en la época clásica ${ }^{13}$, y aunque así hubiese sido, Finazzi ${ }^{14}$ considera la posibilidad de que ésta se haya presentado solo entre los jurisconsultos de la escuela sabiniana ${ }^{15}$.

(otra está en CJ. 2,18(19)24), la cual, sin embargo, fue rechazada por Paulo, siguiendo la opinión de Pomponio.

9 Sobre esta disputa véase SCIAlOJa (1889), pp. 2 y ss.; PACCHIONI (1893), pp. 669 y ss. y PACCHIONI (1935), pp. 561 ss.; Cogliolo (1890), pp. 11 y ss.; GlüCK (1888), pp. 180 y s.; AtZerI (1898), pp. 40 y ss.; Cavallaro (2001), pp. 140; Finazzi (2003), pp. 558-570; Prado RodríGuez (2009), pp. 1-31. Para PACCHIONI (1935), p. 552, la cuestión adquiere mayor interés desde la perspectiva de la solutio.

10 Así, el supuesto del negotium alienum prohibente domino utiliter coeptum determinó un debate sobre el reconocimiento de la actio negotiorum gestorum adaptada en vía útil para el regreso, confróntese Guarino (2001), pp. 965 y ss.

11 Véase EMUNDS (2007), p. 360.

12 Schulz (1930), pp. 238 y ss., confróntese Finazzi (2003), p. 560.

13 Opinión cuestionada por Schindere (1966), pp. 126 y ss., confróntese asimismo, Finazzi (2003), p. 560. En efecto, una tal controversia sobre la gestio prohibente domino no figura entre aquellas referidas por FALCHI (1981), pp. 280, ni tampoco por BAVIERA (1898), pp. 140; sin embargo, según este autor (p. 119): «uno studio più lungo poi e più profundo sulle fonti potrebbe fare scoprire qualche altra controversia che i compilatori nel modo risaputo facevano sparire ma non così bene da non lasciarne una lieve traccia».

${ }^{14}$ FinazZI (2003), p. 563, nt. 193.

15 En efecto, según FinazzI (2003), p. 563, nt. 193, no es seguro que la locución "sed quidam" haga referencia a Próculo, en cuanto que su identificación como favorable no se justifica con base en D. $14,3,17,4-5$, texto que trata de un caso diverso, el del crédito hecho al institor en contra de la prohibición del dominus, y en el que surgía la posibilidad de aplicar las acciones de peculio y de in rem verso, confróntese SCIAlOJA (1889), p. 10. Sin embargo, observa GLÜCK (1888), p. 180: «Fra $i$ vecchi giurisconsulti Proculo e Giuliano si disputava se chi avesse assunto, malgrado il divieto, $i$ negozzi altrui e li avesse utilmente amministrati potesse almeno pretendere la rifusione delle spesse con un'actio utilis neg. gest. Proculo stava per l'affermativa per raggioni d'equità». En este sentido, Proculo estaría a favor de mantener la aequitas, y por consecuencia, de forma implícita se podría indicarlo como favorable a la actio utilis. Por otra parte, tampoco resultaría atendible la referencia al efecto liberatorio de la solutio invito debitore en D. 3,5,38(39), al que atribuyó relevancia CoGLıolo (1890), p. 11, al observar que Gayo y Papiniano (en D. 17,1,53), habrían admitido la actio negotiorum gestorum contraria en consecuencia de la extinción de la deuda ajena. Así, la imposibilidad de dar relevancia a la concesión de la actio utilis deriva de la escasez de opiniones favorables a ella, junto 


\section{La función de la actio utilis para el supuesto prohibente debitore}

Para el derecho clásico, la actio utilis fue una expresión técnica que designaba la extensión analógica, por razones de equidad y de utilidad práctica, de una acción preexistente a hipótesis en las cuales ésta no estaba prevista ${ }^{16}$. Según Valiño ${ }^{17}$, la locución actio utilis se emplearía en dos grandes grupos: el primero para las acciones ficticias y las Ilamadas cognitorias; el segundo para las acciones con trasposición de sujetos y aquellas in factum.

Respecto al supuesto prohibente debitore, la doctrina aproxima la extensión de las acciones útiles con aquellas ficticias y con aquellas in factum. Así, para las primeras, su extensión tenía lugar a través de una fictio iuris ${ }^{18}$, introduciendo en la intentio un hecho diferente al contemplado en la cláusula edictal ${ }^{19}$.

a la autoridad que gozaban los prudentes que estaban en contra, confróntese FinAzZI (2003), p. 570. Por otra parte, se ha tratado de admitir el derecho de regreso a favor del gestor prohibente domino sobre la base de la utilidad pública, la misma que es referida por Ulpiano en D. 11,7,14,13, véase al respecto SiLLA (2007), pp. 645 y ss.

${ }^{16}$ Siendo dicha extensión la característica que la distingue, y no la creación de una nueva acción por el magistrado, confróntese Talamanca (1987), pp. 62 y s.

17 VALIÑO (1974), pp. 22 y s.

${ }^{18}$ La tesis de que las actiones utilis son por naturaleza ficticias se fundamenta en las argumentaciones de VALIÑO (1974), quien afirma en p. 23: "[...] el último sentido que tienen las acciones ficticias es el de salvar un requisito civil con el fin de alcanzar soluciones más justas". Esta resulta ser también la postura de SOTTY (1977), p. 1. De su parte, García GarRido (1957-1958), p. 310, considera la ficción jurídica como una invención que rompe los cánones de la lógica para dar entrada a una innovación que prescinde de la realidad jurídica, siendo un medio al que recurre el Pretor para obviar un obstáculo que se opone a la concesión de una acción. A tal respecto, observa CANNATA (1982), p. 84: «In forza della fictio, il giudice doveva infatti considerare como esistenti circonstanze di fatto o di diritto che in realtà non esistevano, ma che, suppostane l'esistenza, sarebbero stati sufficienti a ricondurre il caso nella sfera di applicazione del ius civile». Por lo tanto, en su significado original, actio utilis equivalía a ficción; así, Gayo (IV, 38) designa como utilis a las acciones que en su intrínseca extensión eran concedidas fuera de un preciso esquema de previsión del edicto del Pretor, lo que se traducía en un alargamiento de la tutela procesal a situaciones análogas a las que correspondían una determinada acción, y esto por utilidad práctica, confróntese CenderelLI (1997), p. 205.

${ }^{19}$ Confróntese Talamanca (1987), p. 62, nt. 447. Al respecto, manifiesta Cannata (1982), p. 84: « [...] la fictio non è una clausula autonoma, individuabile, bensì un elemento dell'intentio: con il termine 'fictio' si allude, perciò, al fatto che qualcosa si finge, e non a una pars formulae». De su parte, observa Fernández BarReiro (1971), p. 714: "[...] las fórmulas pretorias con ficción presuponen acciones civiles, alguno de cuyos requisitos remueven. Tenemos, así, acciones civiles que se pueden utilizar en supuestos distintos de los previstos, gracias a la ficción introducida por el Pretor en la fórmula, y de ahí el nombre de actiones utiles con que aparecen técnicamente designadas estas acciones. En el proceso formulario, por consiguiente, actio utilis equivale a acción con fórmula ficticia [...]". 
En este sentido, nacían por la analogía con otras acciones ya admitidas y conllevaban las mismas consecuencias de la utilidad civil ${ }^{20}$; por ello se Ilamaron acciones útiles, porque hacían referencia a una situación análoga a otra, pero que carecía de algún elemento de hecho o de derecho ${ }^{21}$, para así pasar por idénticas ante el Pretor $^{22}$. Con respecto a aquellas in factum, estas eran concedidas por el Pretor casi siempre en contra del autor de un hecho doloso digno de sanción, en complemento de otras acciones edictales, sin que su fórmula tenga nada que ver con la de aquellas ${ }^{23}$.

Así pues, la función que desempeñaría la actio utilis para el supuesto prohibente debitore se sustanciaría en reestablecer el equilibrio quebrantado por el enriquecimiento injustamente verificado en el deudor principal ${ }^{24}$.

Ante lo cual, la doctrina romanista plantea diferentes opiniones respecto a la identificación de la acción que se adaptaría en vía útil para contrastar el desequilibrio entre las partes de la obligación.

Por una parte, Finazzi ${ }^{25}$ considera que para alcanzar el equilibrio en tal supuesto se habría procedido a través de la adaptación en vía útil de la actio negotiorum gestorum ${ }^{26}$, ordenando al juez que, mediante una fictio, decida

${ }^{20}$ Observa Talamanca (1987), p. 63: «[...] con actio utilis non si indichi una categoria di azioni, ma il fatto che si renda efficente, utilis in questo senso, un'azione, edittale, che non potrebbe esser applicata nel caso in quastione: ciò che avviene [...] mediante un qualche adattamento della formula edittale, la quale ne mantiene, però, intatta l'intentio». En este sentido, para Berger (1953), p. 347, las actiones utiles fueron introducidas por el Pretor para modificar una fórmula ya existente y tutelar así situaciones jurídicas para las cuales la fórmula original no era suficiente, acciones estas que originalmente se Ilamaban directa. Por lo que constituyeron la actividad creadora del Pretor, confróntese SOTTY (1977), p. 1.

${ }^{21}$ De su parte, observa D'Ors (2004), p. 135: «Acciones con ficción, en las que se manda al juez que dé por existente un hecho inexistente, o por inexistente uno realmente existente, a fin de conseguir un resultado justo que, según el derecho civil, se ve impedido por algo que debe ser soslayado». Sobre la posibilidad de paralizar o no a la actio utilis con una exceptio utilis, véase BETANCOURT (1980), pp. 699-719.

22 Sin embargo, observa Buonamici (1886), p. 158, como el ingenio de los romanos distinguió los supuestos en los que, para extender la aplicación de una máxima jurídica, era suficiente la evidente analogía, y no fue necesario fingir el hecho específico establecido por la ley.

23 Confróntese Valiño (1974), pp. 23 y s.

${ }^{24}$ Así, con respecto al carácter ficticio de de dicha acción, observa BIANCHI (1997), p. 345: «Questa cosciente alterazione del dato reale risulta, comunque, sempre giustificata da ragioni di aequitas. Ciò è, del resto, insito nel fatto stesso che codeste fictiones pretorie correggono i rigori del ius civile».

25 FinazZI (2003), p. 563.

${ }^{26}$ A tal respecto observa VALIÑO (1974), p. 24: «El hecho de que algunas poquísimas acciones in factum aparezcan concedidas como útiles, sin lugar a dudas se debe a una alteración del texto clásico, puesto que las acciones básicas que aparecen como útiles son todas acciones in ius conceptae, cuyo formalismo trata de salvar el Pretor, en determinados casos concretos, ordenando al juez que se sirva 
como si el deudor no hubiese manifestado su prohibición a la intervención ajena ${ }^{27}$, considerando así como inexistente aquel elemento o cualidad jurídica que habría imposibilitado la aplicación de una determinada acción civil, y que en el supuesto examinado sería la prohibitio domini ${ }^{28}$.

En este sentido, la aplicación de la actio utilis a través de la adaptación de la negotiorum gestorum ${ }^{29}$ se basaría por ser esta la acción que más se aproximaba al supuesto de quo en virtud de la analogía con la negotiorum gestio, siendo la prohibitio domini el factor diferenciador ${ }^{30}$. Así, la ficción radicaría en la superación del obstáculo jurídico identificado en la prohibición del deudor a que el solvens intervenga en su favor ${ }^{31}$.

De igual manera, Frezza ${ }^{32}$ considera que la acción aplicable al supuesto de D. 17,1,40, sería la negotiorum gestorum adaptada en vía útil33, la cual,

de las ficciones, pues la existencia de éstas presupone necesariamente un obstáculo del ius civile que debe ser evitado [...]». Sobre el recurso a la ficción por el Pretor en las acciones negotiorum gestorum, véase las referencias de García GarRIDO (1957-1958), p. 321, nt. 39.

27 Con respecto a la ficción en su relación con las acciones in factum, observa GuzMÁn BRITO (1978), p. 19: "La ficción, como instrumento de la técnica formularia, funcionaba para superar el derecho civil; pero, junto a las acciones portadoras de ficciones, existían las acciones in factum, cuya función resultaba igualmente superadora de aquel derecho".

${ }^{28}$ Para Guzmán Brito (1978), p. 9, las ficciones pretorias recaían sobre lo que él Ilama calidades jurídicas, y jamás sobre hechos del mundo material, ya que para estos se concedían las acciones in factum. A tal respecto, el autor (p. 19) distingue entre la acción ficticia de aquella in factum, observando: "Si se trataba de producir determinados efectos jurídicos para cuya producción se alzaba en contra un elemento o cualidad jurídicos prescritos por el derecho civil, en el caso concreto realmente existentes o inexistentes, entonces la manera de pasar por sobre ellos era fingir su inexistencia o su existencia, según el caso. Si, en cambio, el defecto o el exceso impedientes de la producción de determinados efectos estaba constituido por hechos del mundo material, entonces lo propio era dar una acción in factum [...] pues, podría decirse que con la ficción se supera un elemento jurídico, mientras que con la acción in factum se supera un elemento de hecho". En este sentido, surge la cuestión acerca de la improcedencia de la adaptación en vía útil de la actio negotiorum gestorum cual acción in factum para el supuesto prohibente domino, al ser la prohibición un elemento jurídico, mas no un hecho material. Ante lo cual, VALIÑO (1974), p. 24, considera que si algunas acciones in factum aparecen concedidas como útiles, se debe a una alteración justinianea.

${ }^{29}$ Sobre la respectiva fórmula, véase Mantovani (1999), pp. 49 s., nt 157.

${ }^{30}$ Confróntese FInAzZı (2003), p. 563. En este sentido, resulta interesante evidenciar como los compiladores hayan colocado en el Codex la constitución con el responsum de Justiniano referente a la gestio prohibente domino $(2,18(19), 24)$ al final del título De negotiis gestis.

31 De esta forma, la prohibición constituiría un obstáculo identificado como el elemento o cualidad jurídica, propio de las acciones ficticias, y no un elemento de hecho del mundo material, que, según GuZMán (1978), p. 19, daría lugar a una actio in factum.

32 FreZZa (1962), p. 193.

33 En efecto, señala FrezzA (1962), p. 193: «Non è esperibile l'actio mandati in nessun caso; è esperibile I'actio negotiorum gestorum, che diventa, nel caso di gestione vetante domino, l'actio utilis neg. 
al estar basada en la utilidad efectiva que obtuvo el deudor, no presuponía de todos los requisitos de la ordinaria negotiorum gestorum ${ }^{34}$, debiendo aplicarse de forma equitativa para actuar el regreso, pero en el límite del injusto enriquecimiento obtenido por el deudor ${ }^{35}$.

Así, y con respecto al significado inherente a la utilitas consiguiente a la gestión ${ }^{36}$, cabe observar la dialéctica entre el utiliter coeptum y el utiliter gestum, en el que el primero concernía a la utilidad de la gestión en su momento inicial ${ }^{37}$, mientras que el segundo, a la utilidad en su conjunto ${ }^{38}$, la cual fundamenta el derecho del gestor a pretender que el dominus negotii se asuma los gastos generados por el negocio gestionado ${ }^{39}$.

gestor. per quei giuristi che l'ammettevano [...]». También SEILER (1968), p. 88, considera que la actio utilis referida en el texto sería la negotiorum gestorum contraria adaptada en vía útil; y a pesar de que el texto habría sido manipulado por los compiladores, no se debería excluir su aplicación para actuar el regreso, confróntese LuZZATto (1969), pp. 482 ss. Por lo que VAliÑo (1974), p. 219, hace referencia a las afirmaciones de Seiler sobre la originalidad clásica de la actio negotiorum gestorum utilis para el supuesto prohibente domino con base en los textos de D. 17,1,40 y CJ. 2,18(19),24. Sin embargo, el mismo VALIÑo (1974), p. 418 no comparte la opinión del Seiler respecto a que «los únicos casos en los que aparece en Derecho clásico una actio utilis negotiorum gestorum son D. $17,1,40$ y C. $2,18,24 »$.

${ }^{34}$ Confróntese SCialoja (1889), p. 5.

35 Por lo que esta actio utilis asumiría la función de una acción de enriquecimiento, véase Rıccobono (1917), p. 22. En este sentido, observa FinazzI (2006), pp. 159 y s.: «Nel caso della gestio prohibente domino è dubbio se i giuristi che ammetevano l'impiego dell'azione utile e di quella volgare prevedessero la limitazione all'arricchimento. Sebbene, nelle uniche fonti in cui tale fenomenologia è pressa in considerazione, Ulp. 10 ad ed. D. 3,5,7(8),3, Paul. 9 ad ed., D. 17,1,40 e lust. C. 2,18(19),24 [...] non ne sia fatta parola, i giuristi dell'epoca moderna ricavavano la limitazione dal confronto con il caso della gestio sui lucri causa menzionata in Ulp. 10 ad ed. D. 3,5,5,5(6)».

36 Sobre el tema véase Finazzi (2003), pp. 501 y ss.

37 Véase Ulpiano en D. 3,5,9(10), 1.

38 Señala FinazZI (2003), p. 503, como a veces la locución utiliter gestum se lo entendía cual sinónimo del utiliter coeptum, "nel senso che la gestione utile è quella utilmente intrapresa». Asimismo, sobre ambos significados observa Díaz DE ENTRE SOtos (1990), pp. 160 y s.: «Utiliter coeptum implica emprender una acción útilmente, aunque de ella no resulte provecho alguno. Por el contrario, el utiliter gestum exige que se produzca un resultado útil, ventajoso para el dominus». Véase también SÁNCHEZ (2000), pp. 223 y ss.

39 El gestor debía administrar el negocio de manera útil para el dominus negotii, ya que así nacía su derecho al reembolso con la actio negotiorum gestorum contraria. En el supuesto de la solutio ignorante debitore, éste tenía la obligación de ratificar la gestión que le haya aportado resultados útiles, como era la extinción de su deuda, confróntese SERRAO (1947), p. 104. Surge así la necesidad de que el deudor ratifique la gestión cuando obtuvo de ella una utilidad efectiva, al ser la solutio del tercero considerada un bien no solo para el deudor sino también para la comunidad, confróntese D. 3,5,38(39) y D. 46,3,53, ya que la ratificación hacía incontestable su utilidad y eliminaba la eficacia de una precedente prohibitio, confróntese TALAMANCA (2001), p. 316. 
Sin embargo, y con respecto a la intervención prohibente debitore, hay que observar cómo, desde el momento que se manifestó la prohibición a la injerencia del tercero, la gestión careció del utiliter coeptum ${ }^{40}$ y, por consiguiente, no se configuraría una negotiorum gestio. No obstante, en tal supuesto sí se evidencia el utiliter gestum, ya que la solutio del tercero, aunque prohibida, ha comportado una utilidad efectiva para el deudor al liberarlo del vínculo obligacional que lo tenía atado a su acreedor.

Así pues, la tesis favorable a la adaptación en vía útil de la actio negotiorum gestorum estaría fundamentada en el mantenimiento de la aequitas y en la necesidad de evitar que el deudor se enriquezca de forma injustificada con detrimento ajeno ${ }^{41}$, ya que, a pesar de que estuvo contrario a la intervención del solvens, se vio de todos modos librado de su deuda sin dar nada a cambio ${ }^{42}$.

De esta forma, la actio negotiorum gestorum en vía útil iría más allá de ser el instrumento procesal concedido ante una gestio ignorante domino ${ }^{43}$, de manera que su fórmula presentaba la ficción de que el deudor jamás prohibió la intervención del solvens ${ }^{44}$, determinado los presupuestos para efectivizar su derecho de regreso y mantener así la aequitas entre las partes ${ }^{45}$, evitando un injusto enriquecimiento para el deudor.

\footnotetext{
40 Confróntese Pasquau (1986), p. 96.

${ }^{41}$ Con base en ello se consideró a las actiones negotiorum gestorum como acciones de enriquecimiento, por lo que la teoría sobre el utiliter gestum que exigía una utilidad permanente coincide con aquella sobre el enriquecimiento injustificado; habría sido Justiniano quien, al extender el ámbito de aplicación de las actiones negotiorum gestorum, les confirió la función de una acción de enriquecimiento, véase RicCOBOno (1906), pp. 203 ss. y RicCOBOno(1917), pp. 17 y ss.; ZimmermanN (1990), pp. 875 y ss.

42 Confróntese Cavallaro (2001), p. 9.

${ }^{43}$ En la que se aplican las acciones 'quae appellantur negotiorum gestorum' (J. 3,27), confróntese Nicosia (1969), pp. 628 y ss.

${ }^{44}$ Lo que le permitiría proceder para el regreso en calidad de negotiorum gestor, véase ATZERI (1904), pp. 244 y ss.; EMUNDS (2007), pp. 337 y ss. Al respecto, en D. 3,5,38(39), D. 3,5,20(21) pr., D. $3,5,42(43)$, D. $46,3,23$ y D. $46,3,53$, se evidencia el factor de la ignorantia debitoris, donde la consecuencia era que el solvens proceda para el regreso con la actio negotiorum gestorum contraria al intervenir sin haber recibido encargo, ni por la ley, ni por el interesado, entrometiéndose al objeto de evitarle un perjuicio al deudor a causa de la mora o de su insolvencia, confróntese GIRARD (1909), pp. 638 y ss.

${ }^{45}$ En efecto, observa Buonamici (1886), p. 160, como las actiones utiles se admitían « [...] a cagione della equità dall'insieme dei fatti».
} 
Por otra parte, Valiño ${ }^{46}$ considera que adaptada en vía útil haya sido la actio mandati contraria ${ }^{47}$, lo cual podría resultar admisible desde el momento que la fianza pudo haberse constituido mediante un mandato, el cual posteriormente fue revocado y prohibida la intervención del garante ${ }^{48}$.

Desde otro interesante punto de vista, Sotty ${ }^{49}$ considera que la actio utilis referida en el texto de Paulo sería la acción que poseía el acreedor satisfecho, y que de forma útil habría sido cedida al solvens para que proceda en contra del deudor en calidad de su nuevo acreedor ${ }^{50}$. En efecto, se sabe que desde la época clásica el solvens podía hacerse ceder las acciones del acreedor satisfecho a través de la cessio actionum, las cuales aún no se habrían extinguido por la litis contestatio para ir en contra del deudor y así obtener el regreso, por lo que de todas formas el deudor estaba obligado a extinguir su deuda, sea directamente a su acreedor o al tercero solvens que lo liberós1.

No obstante la referida discusión doctrinal, parecería más factible entender que ante una gestión prohibida se haya admitido la actio negotiorum gestorum utilis, es decir, fingir que el deudor jamás prohibió la intervención ajena y, por consecuencia, suponer el estar ante una gestio ignorante domino, que, por el contrario, forzar la admisión de una actio mandati utilis, y fingir que se haya dado un mandato cuando no lo hubo y, más bien, se prohibió la intervención ajena desde el inicio ${ }^{52}$.

Por lo tanto, cabe admitir la aplicación de la actio negotiorum gestorum adaptada en vía útil para el supuesto prohibente debitore, ya que la ratio de

\footnotetext{
${ }^{46}$ VALIÑO (1974), p. 218.

47 Sobre esta acción véase MANTOVANI (1999), p. 49, nt. 15 y p. 184, n. 37.

${ }^{48}$ El texto de Paulo no menciona los antecedentes previos al supuesto narrado. Sin embargo, es sabido como la fianza se constituía, por lo general, previo mandato con el deudor, confróntese Frezza (1962), p. 159; véase también Talamanca (1968), pp. 322 y ss.; Bernad Segarra (1999), pp. 325.

49 Sottr (1977), pp. 257 y ss. y (1979), p. 152.

${ }^{50}$ Observa SotTy (1977), p. 259: «L'action utile vise par ce texte est l'action du créancier donée utile au fidéjusseur contre le débiteur, contraint de défendre à l'action sur une formule avec transposition de personnes, bien qu'il n'y ait pase u cession de l'action au fidéjusseur». Sin embargo, comentando a este autor, FINAZZI (2003), p. 563 manifiesta: «È più difficile verificare le opinioni secondo le quali si tratterebbe dell'azione spettante al creditore concessa al fideiussore solvente con trasposizione di soggetti».

${ }^{51}$ Confróntese Guzmán (1996), p. 93. Véase al respecto Vigneron (1974), p. 443; Briguglo (1999), pp. 464; Provera (1983), pp. 609-659.
}

52 Sin embargo, cabe observar como Pothier (1824), p. 302, define a la negotiorum gestio como una especie de mandato ficticio, lo que permite no excluir del todo la idea de la aplicación de dicha actio mandati utilis. 
dicha acción era la de mantener la aequitas entre las partes de la obligación ${ }^{53}$, y así evitar un enriquecimiento injustificado para una de ellas ${ }^{54}$, según el razonamiento de algunos glosadores que también se pronunciaron sobre dicha cuestión ${ }^{55}$.

Por consecuencia, se contrastaría la injusta locupletatio del deudor con el consiguiente quebrantamiento de la equidad natural, la cual prohíbe que nadie se enriquezca con daño ajeno ${ }^{56}$, según los principios establecidos en D. $12,6,14$ y en D. 50,17,206, fuentes que aluden a la aequitas naturalis entendida como la justicia distributiva ${ }^{57}$, y aunque las máximas no refieren explícitamente a la restitución que estaría obligado el injustamente enriquecido, esta resulta intrínseca en dichos principios ${ }^{58}$.

Sin embargo, queda latente la cuestión acerca de que la actio negotiorum gestorum era una acción in factum y no en ius conceptae, en la que sí habría sido factible la aplicación de la ficción ${ }^{59}$. A este respecto, podría admitirse la tesis referente a que los compiladores habrían utilizado indistintamente los

53 Al respecto, Riccobono (1937), p. 210, considera a la aequitas como lo que en la conciencia común es justo para todos igualmente. Sobre la naturaleza de la referida aequitas, véase RIPOSATI (1965), pp. 447 y ss.

${ }^{54}$ Sobre la teoría romana del enriquecimiento injustificado y las acciones dirigidas a contrastarlo, véase Astuti (1958), pp. 52-63; KupISCH (1994), pp. 423-436.

55 En efecto, Martino Gosia admitía una actio utilis ex aequitate en una de las dissensiones dominorun del título 'An is qui prohibente domino negotia gessit actionem per expensis habeat, al contrario de la mayor parte de los maestros que negaban todo tipo de acción, según la frase del texto de la dissensio, "nec directam nec utilem habet actionem de inpensis, ut C. de negotiis gestis I. ult. et D. mandati l. si pro te et D. de negotiis gestis, I. ex duobus", confróntese Hänel (1934), p. 241; Hugolinus §33, 275; Scialoja (1889), p. 11; Rivalta (1895), pp. 109 y ss.; Cavallaro (2001), p. 16; Hallebeek (1995), pp. 70 y ss.; LuIG (2005), pp. 53 y ss. Observa al respecto FinazZI (2003), p. 15: «I glossatori discutevano circa I'azionabilità della gestio prohibente domino, per la quale Martino ed entro limiti circoscritti Azone, diversamente dalla maggior parte dei contemporanei, ammettevano l'actio negotiorum gestorum utilis: oltre che dal materiale della compilazione giustinianea [...] la concessione de aequitate potrebbe essere dipesa in qualche misura anche dalla difficoltà di ammettere l'integrazione della negotiorum gestio sul piano dello strictum ius in difetto della volontà del dominus negotii». También PiLII Medicinensis (1560), pp. 10 y s., admitió una actio negotiorum gestorum utilem para tal supuesto en la Questio VI de sus Quaestiones Sabbatinae del título An solvens pro t(e) ne damnun pateretur, possit solutum repetere et qua actione, véase CaVallaro (2001), pp. 37 y ss.; Rivalta (1865), pp. 114 y ss.; Belloni (1989), pp. 127-130.

56 Confróntese Rıccobono (1915), p. 374.

57 Respecto al encuadramiento jurídico de la persona del enriquecido, estos aparecen de la locución 'fieri locupletiorem', mientras que la referencia al empobrecido está en la frase 'cum alterium detrimento', confróntese CanNATA (2005), p. 24.

${ }^{58}$ Confróntese Cannata (2005), p. 24.

59 En efecto, según D’Ors (2004), p. 135, nt. 3: «La fórmula ficticia se basa en una intentio in ius; no se adapta, pues, a las fórmulas in factum. De este sentido de utilis hay que distinguir el de simple 
términos utilis e in factum en su respectiva aplicación ${ }^{60} \mathrm{O}$, según Valiño ${ }^{61}$, que hayan alterado los textos en los que aparecen las acciones in factum concedidas como útiles.

\section{La postura de Justiniano ante la cuestión prohibente domino: la referencia a la actio utilis en CJ. 2,18(19),24}

Con respecto a la época justinianea, en CJ. 2,18(19),2462 aparece otra mención a la actio utilis como posible recurso para obtener el regreso; en efecto, en el texto de la constitución imperial se informa sobre una disputa surgida entre los antiguos jurisconsultos respecto al derecho de regreso consiguiente a la gestio prohibente domino ${ }^{63}$, y en la que algunos estimaban oportuno conceder una directam o utilem actionem, mientras que otros la negaban, entre los que estaba Juliano ${ }^{64}$, a cuyo parecer se acogió Justiniano al excluir toda acción en favor del gestor ${ }^{65}$.

conveniencia o eficacia de una acción, como cuando se emplea utilis en función de predicado [...] o el adverbio utiliter (agere) [...]».

${ }^{60}$ Confróntese D'Ors (2004), p. 135, nt. 3.

${ }^{61}$ VALIÑO (1974), p. 24.

${ }^{62}$ CJ. 2,18(19),24: Imp. IUstinianus A. IOANNI P.P. Si quis nolente et specialiter prohibente domino rerum administrationi earum sese immiscuit, apud magnos auctores dubitabatur, si pro expensis, quae circa res facta sunt, talis negotiorum gestorum habeat aliquam adversus dominum actionem. Quam quibusdam pollicentibus directam vel utilem, aliis negantibus, in quibus et Salvius Iulianus fuit, hoc decidentes sancimus, si contradixerit dominus, et eum res suas administrare prohibuerit, secundum Iulianu sententiam nullam esse adversus eum contrariam actionem, sicilicet post denuntiationem, quam ei dominus trasmiserit, non concedens ei res eius attingere, licet res bene ab eo gestae sint. Quid enim, si dominus adspexerit ab administratore multas expensas utiliter factas, et tunc dolosa assimulatione abita eum prohibuerit, ut neque anteriores expensas praestet? Quod nullo modo patimur; sed ex quo ea testatio ad eum facta est vel in scriptis vel sine scriptis, sub testificatione tamen aliarum personarum, ex eo die pro faciendis meliorationibus nullam ei competere actionem, super anterioribus autem, si utiliter factae sunt, habere eum actionem contra dominum concedimus sua natura currentem. Dat. XIV. Kal. Dec. Constant. LAMPADIO et ORESTE Conss. [530.].

${ }^{63}$ Del texto vemos como la supuesta disputa se recaba de la frase 'apud magnos auctores dubitabatur', la cual induce a pensar que en la época clásica existió la posibilidad de concederle al gestor una actio utilis basada en la aequitas y en el principio que prohíbe el enriquecimiento injustificado (D. 12,6,14 y D. 50,17,206). Véase FinazzI (2003), p. 559.

${ }^{64}$ Observa Finazzı (2003), p. 560, como hacia finales de la época clásica, la opinión de Juliano fue ampliamente reconocida y aceptada. Al respecto, el texto en el que Juliano, junto a Ulpiano, excluyen el derecho de regreso está en D. 3,5,7(8),3, en el que, sin embargo, no hay referencia explícita a la actio utilis, véase VALIÑO (1974), p. 217.

${ }^{65}$ Esta decisión no habría considerado la relevancia de la utilidad efectiva que recibió el dominus negotii al obtener un enriquecimiento injustificado por la gestio realizada en su favor, por lo que 
Así, gracias al referido texto podemos conocer el estado de la cuestión para la época anterior a la emanación de la constitución colocada en CJ. 2,18(19),24, en la que hubo una corriente favorable al derecho de regreso para el gestor prohibente domino ${ }^{66}$. En este sentido, a pesar de que en D. 17,1,40 y en CJ. 2,18(19),24 se excluyen todas las acciones para actuar el regreso, al mismo tiempo mencionan a la actio utilis, circunstancia esta que abre la vía para plantear su posible aplicación ${ }^{67}$.

Sobre la referencia en el texto imperial a la actio directa, del contexto de CJ. 2,18(19),24 parecería que Justiniano quería indicar a la actio negotiorum gestorum contraria, es decir, a la acción concedida al gestor en contra del dominus negotii para el regreso de los gastos útilmente realizados en su fa$v r^{68}$, a pesar de que dicha acción no podía admitirse al no darse los requisitos propios de la negotiorum gestio ${ }^{69}$.

Sin embargo, puede ser que Justiniano haya querido referirse en realidad a la función que tuvo en origen la actio directa ${ }^{70}$, al ser esta la acción original,

debía restablecerse la aequitas quebrantada a causa de la injusta locupletatio, confróntese ZACHARIAE (1867), p. 261, nt.1.

${ }^{66}$ A tal respecto, señala $V_{\text {ALIÑO }}$ (1974), p. 218: «Esta constitución [...] contiene una referencia histórica de gran valor, porque el emperador viene a referir en ella el estado del derecho anterior y gracias a él sabemos que algunos juristas se manifestaron en favor de la actio negotiorum gestorum utilis en el caso de gestión prohibente domino»; véase también Cenderelli (1997), pp. 202 y ss.

${ }^{67}$ En efecto, si el gestor no hubiese tenido alguna posibilidad de obtener el regreso, dichas fuentes no habrían mencionado a la actio utilis; sin olvidar que la utilidad obtenida por el dominus, y el consiguiente quebrantamiento de la equidad natural que prohíbe que nadie se enriquezca con detrimento ajeno, la justificaría. Asimismo, la referencia a estas dos acciones hace suponer que si se negaba la utilis, habría sido posible proponer la directa, en cuyo caso no habría sido necesario acudir a ninguna fictio iuris, por lo que además, no se excluiría tampoco que se tratase de una actio cognitoria clásica, pudiendo inclusive pensar que se haya admitido la actio mandati utilis para el regreso, según lo considerado por VALIÑO (1974), p. 218.

${ }^{68}$ Observa FinazzI (2003), p. 564, nt. 194: «Come sembra emergere dal contesto della costitutzione, Giustiniano doveva avere presente l'actio negotiorum gestorum contraria, non l'actio spettante al creditore e da questi ceduta espressamente al fideiussore». Y era sobre este último sentido que se había pronunciado Sotty (1977), p. 258. Sin embargo, observa Cenderelli (1997), p. 202, que la referencia directam actionem sería utilizada por los clásicos en un sentido diferente a la contraposición justinianea directa-contraria, lo cual determinó que tal terminología no fuere habitual para entonces, siendo una innovación justinianea, véase también el mismo Cenderelli (1999), pp. 289 y ss.

${ }^{69}$ En consecuencia, los términos directa y contraria no habrían sido utilizados de forma precisa, véase Bortolucci (1909), pp. 18 y ss.; Cenderelli (1997), p. 197 y Cenderelli (1999), p. 291.

70 Según BeRGER (1953), pp. 345 y s., las acciones directae eran aquellas cuya fórmula podía ampliarse mediante una modificación apropiada a las circunstancias análogas no cubiertas por la fórmula original; así, la fórmula modificada era una actio utilis, en contraposición a la acción original directa. Este era el sentido original, pero luego las acciones fueron Ilamadas por Justiniano contrariae en contraposición a las directae. Véase al respecto Betancourt (1980), p. 700. 
pero denominada utilis cuando se extendía a un supuesto al que no habría podido tener lugar, y que iba más allá de su ámbito de aplicación a través de una fictio iuris ${ }^{71}$, siendo acciones ficticias las utiles in factum ${ }^{72}$.

Así, cuando las fuentes hacen referencia a la actio utilis, no siempre se la debe entender en oposición a la directa, ya que también se habla de esta acción en un sentido vulgar, es decir, como una acción útil y eficaz ${ }^{73}$; en consecuencia, la actio directa habría sido utilizada por los clásicos en los casos en los que se manifestaba la exigencia de distinguirla de aquella concedida en vía útil ${ }^{74}$.

Por lo que, al mencionar CJ. 2,18(19),24 que algunos admitían una actio utilis, se puede concluir que tales acciones eran aquellas pretorias en las que la fórmula contenía una adaptación a las acciones civiles, al objeto de extender su aplicación a situaciones análogas que se salían de su previsión original; además, la inclusión de CJ. 2,18(19),24 bajo el título de negotiis gestis, induce a pensar a una adaptación de la fórmula de la actio negotiorum gestorum mediante la ficción que obligaba al iudex a decidir como si el dominus no hubiese prohibido ${ }^{75}$, actuándose así un criterio equitativo respecto a la rígida opinión por la cual el utiliter gestum era excluido en la gestio prohibente domino ${ }^{76}$.

\footnotetext{
71 Observa Betancourt (1980), p. 718: "una acción básica (directa) puede ser extendida por el Pretor como utilis, mediante el recurso de la ficción, a un nuevo supuesto de hecho no muy diferente del que contempla la acción básica pero que era inaplicable por faltar a aquél un elemento de ésta".

72 Véase Sottr (1977), pp. 40 y ss. y Sotтy (1979), pp. 152 y ss.

${ }^{73}$ Por lo tanto, vulgar era la acción habitual y usualmente aplicada, confróntese SCIALOJA (1894), pp. 515 y s. En este sentido, se denominó directa o vulgaris la acción que se aplicaba a los casos previstos en origen; por lo que, para BERGER (1953), p. 348, las actiones vulgares eran las opuestas a las utilis.

74 Por lo que para los clásicos la diferencia entre actiones directa y utilis se mantuvo, y posteriormente se reunieron en un único esquema. Así, en relación a los términos directa y utilis, se puede suponer que estos hayan sido el resultado de una imprecisión terminológica, lo cual se constata de un texto atribuido a Paulo, tal vez manipulado, y colocado en D. 3,5,46(47), 1 (1 Senten.): Nec referit directa quis an utili actione agat vel conveniatur, quia in extraordinariis iudiciis, ubi conceptio formularum non observatur, haec suptilitas supervacua est, maxime cum utraque actio eiusdem potestatis est eundemque habet effectum. Aquí se afirma que no importa que cualquiera demande o sea demandado por la acción directa o por la útil, ya que en los juicios extraordinarios, en los que no se observa la solemnidad de las fórmulas, esta sutileza resulta inútil y a mayor razón, cuando ambas acciones producen igual resultado. En este sentido, asistimos a la caída en época justinianea, del riguroso formalismo concerniente a la denominación de las acciones, ya que D. 3,5,46(47) advierte que las actiones directae y utiles tienen la misma eficacia, véase Cenderelli (1999), p. 292; VAliño (1974), pp. 418 y s. Sobre el texto véase Mercogliano (2001), p. 52.

75 Confróntese Finazzi (2003), p. 563.

${ }^{76}$ Confróntese Riccobono (1917), p. 22.
} 
Y en relación a ello, hay que mencionar como para tal contexto, las actiones negotiorum gestorum adquirieron la función de una acción de enriquecimiento en sentido amplio ${ }^{77}$, las mismas que se concedían en los supuestos en los que un sujeto había sufrido un empobrecimiento debido al enriquecimiento injustificado obtenido por otro ${ }^{78}$, explicándose así su carácter subsidiario $^{79}$.

\section{El alcance de la cuestión prohibente debitore en el Código Civil de Bello}

Como es sabido, el Código Civil chileno ${ }^{80}$ fue elaborado por el romanista Andrés Bello ${ }^{81}$, quien para su realización se basó en varias fuentes históricas ${ }^{82}$, así como en las obras de Pothier ${ }^{83}$ y de algunos exégetas franceses ${ }^{84}$ que influenciarían su Código ${ }^{85}$.

Sobre la cuestión prohibente debitore, el Código Civil de Bello presenta una notoria contradicción entre los artículos que regulan el derecho de regreso consiguiente al pago prohibente debitore (1574) y la gestión de negocios ajenos prohibente domino (2291).

En efecto, mientras el artículo 1574 niega el derecho de regreso para el solvens, el artículo 2291 lo admite, estableciendo a fundamento de dicha admisión, la utilidad efectiva que la gestión le aportó al interesado del negocio, viéndose en dicha utilidad el alcance de la romana actio utilis, la cual

\footnotetext{
77 Sería en la época postclásica cuando se creó una sola actio negotiorum gestorum, dentro de la cual se distinguió entre vulgaris seu directa, relativa a la espontánea intromisión, y la negotiorum gestorum utilis, relativa a la gestión necesaria, a pesar de que solo aquella espontánea se consolidaría en el tiempo, confróntese Finazzı (1999), p. 431.

${ }^{78}$ A este respecto, cabe referir la frase final de D. 3,5,5,5, "sed in quod ego locupletior factus sum habet contra me actionem", que evidencia la relación entre la actio negotiorum gestorum contraria y el enriquecimiento injustificado obtenido por el dominus negotii, donde los gastos empleados por el gestor se podían solicitar pero en el límite del enriquecimiento obtenido por el dominus negotii, confróntese FinazZI (2006), pp. 156 y s.

${ }^{79}$ Véase Riccobono (1917), p. 30.

${ }^{80}$ Considerado como un nuevo modelo de codificación dentro del sistema jurídico romanista con respecto a los códigos ya existentes en Europa, confróntese CARDILLI (2004), p. 73.

81 Sobre el proceso de codificación en Chile véase Guzmán (2000), pp. 350 y ss.

82 Señala GuZmán (2006), p. 1290: "Entre las fuentes del nuevo cuerpo legal [...] también intervino directamente el Corpus iuris civilis, que Bello consideraba como la base de la ciencia jurídica". Véase también Guzmán (1992), pp. 81-88; RodríGuez (2012), p. 748.

${ }^{83}$ Confróntese Guzmán (2006), p. 1291.

${ }^{84}$ Véase Alonso (2007), p. 876.

85 Según señala Guzmán (2006), p. 1291, Bello consultó las obras de Toullier, Troplong, Duranton, entre otros.
} 
justifica el derecho de regreso para el solvens al estar dirigida a mantener la aequitas entre las partes de la obligación y así evitar que el deudor se enriquezca injustificadamente ${ }^{86}$.

Sin embargo, antes de analizar la normativa que ha dado lugar a la contradicción existente en el Código, resulta imprescindible evidenciar la postura de Pothier sobre la cuestión prohibente domino, al ser este autor fuente de inspiración para la reglamentación que realizó Bello en el artículo 2291 de su Código Civil ${ }^{87}$.

\subsection{Antecedentes: la postura de Pothier sobre la cuestión prohibente debitore}

Con respecto a la cuestión prohibente debitore, en su Traité du quasicontrat de negotiorum gestorum, precisamente en los numerales del $\$ 180$ al $\S 184^{88}$, Pothier hace referencia a la gestio prohibente domino, citando directamente a las fuentes romanas que se pronunciaron sobre dicha problemática, como son D. 17,1,40 y CJ. 2,18(19)2489.

Así, para el supuesto del pago prohibente debitore, Pothier no estaba de acuerdo en la solución prospectada por Paulo en el texto de D. 17,1,40, al no ser considerada conforme a la equidad natural, la cual no permite que alguien se enriquezca con daño ajeno ${ }^{90}$.

Para tal supuesto, y dado que no se podía proceder con la actio negotiorum gestorum contraria, Pothier considera que se debe admitir una actio in factum dirigida a la repetición de lo pagado en utilidad del dominus negoti ${ }^{91}$.

\footnotetext{
${ }^{86} \mathrm{Al}$ respecto, ya en las Partidas se estableció el principio que prohíbe enriquecerse con perjuicio ajeno, así en la Partida 7,34,17: «E aun dixeron que ninguno non deue enriquecerse torciceramente en daño de otro», véase Dízz-Pıcazo (2011), p. 3030.

${ }^{87}$ Así como se evidencia del Proyecto de Código Civil de 1853, en la nota del artículo 2443 a, equivalente al actual 2291 Cc.ch., véase Bello (1888), p. 579.

88 Pothier (1824), §181, pp. 301 y ss.; véase asimismo, Cavallaro (2001), pp. 85 y ss.; Luig (2005), p. 69.

${ }^{89}$ Véase POthier (1824), \$181, pp. 301 y s.

90 Según Pothier (1824), \$182, p. 302: «Cela ne résiste-t-il pas à l'equité naturelle, qui ne permet pas que vous pussiez vous enrichir à mea dépens? Neminem aequum est cum detrimento alterius locupletari».

91 A tal respecto, Pothier manifiesta que la problemática en cuestión encuentra solución en la jurisprudencia francesa, la misma que no atribuye importancia a los nombres de las acciones, ya que la referida equidad es suficiente para crear una obligación civil y una acción judicial, confróntese POTHIER (1824), §182, pp. 302 y s.

Con respecto a los exégetas franceses, TOullier (1830), pp. 11 y ss., n. 12, negó el derecho de regreso para el solvens prohibente debitore. Por otro lado, estuvieron a favor del derecho de regreso,
} 
Finalmente Pothier señala que, cuando el dominus negotti aprovecha un negocio para él útil, aunque realizado en contra de su voluntad, "l'équité naturelle" lo obliga a indemnizar los gastos que fueron realizados en su utili$\mathrm{dad}^{92}$, pero siempre en el límite de la ventaja patrimonial recabada al tiempo de la presentación de la demanda ${ }^{93}$; para lo cual, el juez deberá facilitar los términos que le solicite el obligado al objeto de efectuar dicho reembolso ${ }^{94}$.

Esta fue la postura de Pothier sobre la cuestión prohibente debitore, por lo que podemos analizar la reglamentación del Código Civil de Bello sobre la contradicción existente entre sus artículos 1574 y 2291, y en la que se podrá evidenciar la influencia que tuvo el autor francés, quien a su vez, tomó como referentes a las fuentes del Derecho Romano ya analizadas.

\subsection{Admisión del pago prohibente debitore en el Código Civil de Bello}

Ante todo, el Código de Bello admite que un tercero pague la deuda ajena ${ }^{95}$ aun en contra de la voluntad del deudor, según lo establece el $1^{\circ}$ inciso del artículo 1572:

Puede pagar por el deudor cualquier persona a nombre del deudor, aun sin su conocimiento o contra su voluntad, y aun a pesar del acreedor ${ }^{96}$.

De la referida disposición se pueden recabar tres intervenciones del tercero solvens ${ }^{97}$ : el pago hecho con el consentimiento del deudor; sin su conocimiento, y en contra de su voluntad ${ }^{98}$, lo cual se fundamenta en el propósito

pero en el límite de la utilidad obtenida por el interesado del negocio para así evitarle un injusto enriquecimiento, juristas como Duranton (1841), p. 12, y Troplong (1846), pp. 21 y ss.

92 Confróntese POthier (1824), §182, pp. 302 y s.

93 En efecto, señala Pothier (1824), §183, p. 303: «[...] car il n’a la répétition de ce qu'il a déboursé, que jusqu'à concurrence de ce que je me trouve enprofiter au temps de sa demande».

${ }_{94}$ Confróntese POTHIER (1824), §183, p. 303.

95 Sobre la concepción dogmática del pago del tercero en el derecho positivo véase TuR (1996), pp. 277; Albiez (1996), pp. 13-88; Bayo (2000), pp. 370; Del Olmo (1998), pp. 416; Turco, L'adempimento del terzo (2002), pp. 236; SerRano (2011), pp. 137-211.

${ }_{96} \mathrm{El} 2^{\circ}$ inciso del referido artículo establece: Pero si la obligación es de hacer, y si para la obra de que se trata se ha tomado en consideración la aptitud o talento del deudor, no podrá ejecutarse la obra por otra persona, contra la voluntad del acreedor. Al respecto, y por lo que se refiere a las prestaciones de dar dinero, se puede suponer siempre el interés del acreedor a ser pagado sin importar por quién; por lo que la voluntad del acreedor tendrá mayor relevancia en el ámbito de las prestaciones de hacer, véase D. 46,3,31; Claro SOlAR (1979), §1338, p. 59.

97 Respecto al animus solvendi, este tiene relación con el animus negotia aliena gerendi, cual intención de gestionar un negocio ajeno, surgiendo la obligación para el dominus negotii de reembolsar al gestor, confróntese GıÜсK (1888), p. 184.

${ }^{98}$ Confróntese Claro (1979), p. 48. 
de mejorar no solo la condición misma del deudor, sino también la de la comunidad $^{99}$.

Así, en primer lugar, al establecer que cualquier persona a nombre del deudor puede pagar su deuda, se puede suponer que el tercero intervenga con el conocimiento y, por consiguiente, con el consentimiento expreso o tácito del deudor, por lo que estaríamos ante la intervención del mandatario del obligado, quien queda subrogado "por el ministerio de la ley en el lugar y derecho del acreedor ${ }^{\prime \prime 100}$.

Por otra parte, la segunda posibilidad que se plantea es que un tercero pueda pagar sin el conocimiento del deudor; en tal supuesto estaríamos ante un gestor de negocios ajenos que interviene de forma espontánea al objetivo de liberar al deudor, sin que este último esté al corriente de la intervención ajena, y cuyo derecho regreso encuentra justificación en la naturaleza misma del cuasicontrato de gestión oficiosa reflejada en la teoría del enriquecimiento injustificado, por lo que podrá ser reembolsado, pero en el límite de lo pagado, sin tener lugar a que la ley lo subrogue en los derechos del acreedor ${ }^{101}$.

La última posibilidad que admite el artículo 1572 es la que un tercero pueda pagar en contra de la voluntad del deudor; este es el supuesto que mayor dificultada ha determinado a la hora de establecer el derecho de regreso en favor del solvens, y que ha dado lugar al surgimiento de una contradicción entre los artículos 1574 y 2291 del Código Civil de Bello ${ }^{102}$.

En efecto, en esta última situación estaríamos fuera de las dos intervenciones anteriores, es decir, la del mandatario solvens, ya que la prohibición del deudor excluye cualquier acuerdo con el tercero para que éste pague en su lugar, y también fuera de la gestión oficiosa, ya que la característica de esta figura radica en que la intervención del tercero solvens se verifique sin

\footnotetext{
${ }^{99}$ Véase D. 46,3,53, Partidas 5, 14, 3; Claro (1979), p. 50.

100 Así Claro (1979), p. 51. Y según lo establece el artículo 1610, numeral 5º, Cc.ch.

101 En efecto, el artículo 1573 Cc.ch. establece: El que paga sin el conocimiento del deudor no tendrá acción sino para que éste le reembolse lo pagado; y no se entenderá subrogado por la ley en el lugar y derechos del acreedor, ni podrá compeler al acreedor a que le subrogue. Del mencionado artículo se recaba que el pago hecho por el gestor oficioso puede obtener solo el reembolso de lo pagado, sin poder repetir los demás gastos inherentes. Asimismo, dicho artículo excluye la posibilidad de la subrogación legal (ex art. 1610), admitiéndose implícitamente aquella convencional (ex art. 1611), confróntese ClARO (1979), p. 51.

102 Este supuesto también se lo puede relacionar con las disposiciones que regulan el pago hecho por un fiador en contra de la voluntad del deudor principal, artículos 2345, 2370 y 2375, véase al respecto SeRrano (2011), p. 196.
} 
el conocimiento del deudor, lo cual no se concreta a causa de la prohibición manifestada por el mismo deudor ${ }^{103}$.

No obstante, en dichas circunstancias quedaría abierta la vía para que el tercero solvens recupere lo pagado mediante la subrogación convencional, es decir, atribuyéndole al acreedor la facultad de cederle al solvens las acciones que disponía para ir en contra del deudor en caso de incumplimiento por parte de este último ${ }^{104}$.

\subsection{Contradicción en la reglamentación del derecho de regreso consiguiente al pago prohibente debitore}

Por lo que concierne a la reglamentación del derecho de regreso consiguiente al pago realizado por el solvens prohibente debitore, el Código Civil de Bello plantea dos alternativas, las cuales, sin embargo, presentan entre ellas una contradicción comúnmente conocida; la primera alternativa se encuentra establecida en el artículo 1574:

El que paga contra la voluntad del deudor, no tiene derecho para que el deudor le reembolse lo pagado; a no ser que el acreedor le ceda voluntariamente su acción $n^{105}$.

El referido artículo excluye el derecho de regreso para el solvens que intervino prohibente debitore ${ }^{106}$, lo cual contrasta con la admisión de esta

\footnotetext{
103 Ambos supuestos aparecen indirectamente referidos en el texto de Paulo colocado en D. 17,1,40, al excluir la admisión de las acciones mandati y negotiorum gestorum contraria.

104 El origen de la subrogación convencional está en la romana cessio actionum, con base en un texto de Juliano establecido en D. 46,1,17 (89. Dig.): Fideiussoribus succurri solet, ut stipulator compellatur ei, qui solidum solvere paratus est, vendere ceterorum nomina. El referido texto determina la necesidad de que el pago y la cesión de las acciones se realicen de forma simultánea, haciendo de la cesión una especie de venta de las acciones por parte del acreedor satisfecho, véase BRIGUGLIO (1999), pp. 262 y ss. Sobre la subrogación convencional véase FERNÁndez (1999), p. 137.

105 El referido artículo es el mismo que aparece en el Proyecto de Código Civil de 1853, colocado en el artículo 1755 sin ninguna nota al pie de donde poder identificar su fuente de inspiración, véase Bello (1888), p. 416. Sin embargo, el mismo Bello, en sus Instituciones de Derecho Romano, señala en el Título 30, al tratar De qué modos expira la obligación, «La solución es la prestación de aquello a que somos obligados [...]; por regla general es recta y eficaz si la hace aquel o se hace aquel que tiene la libre administración de sus cosas; mas no importa que la haga por sí o por otro, o que sea con su consentimiento o contra su voluntad. El acreedor no puede rechazar el pago ofrecido por un extraño, y el que pagó por otro contra su voluntad no tiene acción contra él, si no es que el acreedor le cede la suya», así BeLLo (1981), p. 165.

106 Con respecto a ello, señala Figueroa (1997), p. 158: «Decimos que debe ser una voluntad expresa, pues es difícil suponer que alguien no acepte que se extinga una deuda suya a costa de otro sin tener una razón fundada que lo obligue a manifestarse a través de actos concretos, no hacer nada en un supuesto semejante y luego argumentar que el hecho del pago no lo deseaba, si acreditar [...]
} 
forma de pago establecida en la parte final del $1^{\circ}$ inciso del artículo 1572; sin embargo, la norma deja abierta la posibilidad para el reembolso del solvens, al permitirle utilizar las acciones del crédito que posee el acreedor satisfecho y que de forma voluntaria le cedería para que se dirija en contra del deudor liberado ${ }^{107}$.

No obstante, y por lo que se refiere a la explícita negación del derecho de regreso, se ha considerado que a la base estaría un presunto animus donandi del solvens ${ }^{108}$, lo cual contrastaría con lo establecido en la parte final del mismo artículo, en la que el codificador deja abierta la vía para el reembolso a través de la subrogación convencional ${ }^{109}$.

perjuicio alguno, es una actitud desleal y superflua que no debe ser aceptada». Por otra parte, uno de los problemas que surge del artículo 1574 concierne a la prueba de la prohibición del deudor a que un tercero pague su deuda, la cual fue resuelta por Justiniano en la constitución establecida en CJ. 2,18(19),24, al manifestar que la prohibición a que alguien se entrometa en los negocios ajenos debe resultar de un documento escrito o mediante testimonios que afirmen que el dominus negotii prohibió la intervención ajena.

107 De la referida norma se puede intuir su fundamento en el texto de D. $17,1,40$, en el que se niega toda acción para el regreso, pero en el que se ha podido interpretar la referencia a la actio utilis como la acción que poseía el acreedor satisfecho, y que podía transmitirse al solvens para que proceda en contra del deudor, véase SotTr (1977), 259. Al respecto, si consideramos que por lo general, es interés del acreedor recibir el pago, no resulta lejano el admitir que el solvens llegue a un acuerdo con él para que, si cumple con la obligación, le ceda las acciones para que proceda en contra del deudor, y así obtener el regreso. En este sentido, la vía para obtener el regreso queda abierta, pero subordinada a la voluntad del acreedor, evidenciando que la exclusión del reembolso no es absoluta, confróntese LASTARRIA (1864), pp. 222 y s.

108 Es decir, "una especie de donación en que no interviene la voluntad de beneficiar, por lo cual se presenta como una donación obligada", así Vélez (1926), p. 265. Al respecto, observa Serrano (2011), p. 194, que para explicar la negación del derecho de regreso, el Código ha considerado que el pago haya sido hecho donandi causa con base en el Anteproyecto del Código Civil español de 1851. Sin embargo, es sabido como la donación no se presuma, siendo necesaria la aceptación del donatario, rigiendo además el principio establecido por Paulo en D. 50,17,69 (Sing. de assig. Libert): Invito beneficium non datur; este aforismo va interpretado teniendo presente la esfera privada del deudor a no querer que nadie se entrometa en ella aportándole algún beneficio. Al respecto, se entiende por animus donandi aquel espíritu de beneficencia en su mayor grado de expresión, no solo el querer gestionar en el interés del dominus negotii, pero además el administrar gratuitamente sus negocios, renunciando a cualquier acción para obtener el regreso de los gastos empleados; así, gestiona animo donandi quien renuncia a la actio negotiorum gestio contraria, confróntese PACCHIONI (1935), p. 556.

109 Además, ya el mismo hecho que el solvens solicite el regreso constituye prueba de que no tuvo la intención de donar. En efecto, según observa Llambías (1993), p. 143, n. 90, resulta inconciliable el pago del tercero prohibente debitore como una donación, la cual podría realizarse solo si el solvens desiste del reembolso en contra del deudor. 
Por otra parte, la segunda alternativa planteada por Bello fue la de admitir el derecho de regreso para el solvens prohibente debitore ${ }^{110}$ en el artículo 2291:

El que administra un negocio ajeno contra la expresa prohibición del interesado, no tiene demanda contra él, sino en cuanto esa gestión le hubiere sido efectivamente útil, y existiere la utilidad al tiempo de la demanda; por ejemplo, si de la gestión ha resultado la extinción de una deuda, que sin ella hubiera debido pagar el interesado. El juez, sin embargo, concederá en este caso al interesado el plazo que pida para el pago de la demanda, y que por las circunstancias del demandado parezca equitativo ${ }^{111}$.

Según este artículo, puede demandar el reembolso de los gastos realizados aquel que llevó a cabo un negocio útil para el interesado del mismo, aun en contra de su prohibición, y en el que, a modo de ejemplo, se menciona el supuesto que se hubiese extinguido una deuda del interesado del negocio, que sin la cual habría tenido que extinguirla igualmente el deudor. Sin embargo, el elemento central que fundamenta el derecho de regreso en tal supuesto radica en la utilidad efectiva que obtuvo el interesado del negocio gracias a la intervención del tercero ${ }^{112}$, la misma que, a pesar de haberse prohibido, lo liberó de una obligación a la que estaba igualmente vinculado.

${ }^{110}$ Cabe observar como Vélez Sarsfield siguió esta segunda orientación, y en el $2^{\circ}$ inciso del artículo 728 del Código Civil argentino de 1869, después de admitir el derecho del tercero a pagar aun prohibente debitore, se establecía: "El que así lo hubiese verificado tendrá solo derecho a cobrar del deudor aquello en que le hubiese sido útil el pago". Además, en la nota al referido 728, Vélez afirma: "Cuando damos al que ha hecho el pago acción para cobrar aquello en que el pago le ha sido útil al deudor, le reconocemos solo la acción de in rem verso, que se concede a todo aquel que emplea su dinero o sus valores en utilidad de las cosas de un tercero".

111 El referido artículo es el mismo que aparece en el Proyecto de Código Civil de 1853, colocado en el artículo 2443 a., en cuya nota al pie del inciso $2^{\circ}$, identifica la siguiente fuente de inspiración a «Pothier, Neg. Gest. 193», Bello (1888), p. 579. En efecto, señala Pothier (1824) en el §193, p. 307 de su Traité du quasi-contrat de negotiorum gestorum: " [...] l'action, qui est donnée dans l'espèce de ce paragraphe, n'étant fondée que sur la seule raison de l'équité naturelle, qui ne permet pas de s'enrichir et de profiter aux dépense d'autrui, elle ne peut donner la répétition des impenses à celui qui les a faites, que jusqu'à concurrence de ce que je me trouve en profiter au temps de sa demande». Cabe observar como al \$183, Pohier también hace referencia a la utilidad obtenida por el interesado del negocio al tiempo de la demanda, y a la concesión de un plazo equitativo por parte del juez para el reembolso del obligado.

112 Para Salas (1982), p. 358, una gestión deberá reputarse útil cuando así la hubiere considerado aquel sujeto que interviene como un buen padre de familia. Véase también SÁnchez (2000), pp. 212 y ss.; FinazZI (2003), pp. 501-607; StOlJar (2007), pp. 49 y s. 
En este sentido, de la confrontación de estos dos artículos se ha admitido que se trate de una notoria contradicción en el Código Civil de Bello ${ }^{113}$. No obstante, Claro Solar ${ }^{114}$ excluye una tal contradicción, pero se decanta por dar prevalencia al artículo 2291115, al observar que el 1574 determina la exclusión del derecho de regreso en cuanto con dicha intervención la acción de la deuda deja de existir a causa del pago realizado ${ }^{116}$.

\subsection{La utilidad efectiva de la gestión como fundamento del derecho de regreso}

Así, la tendencia prevalente ha sido la de decantarse por lo establecido en el artículo $2291^{117}$, y admitir el derecho de regreso para el solvens prohibente debitore sobre la base de la utilidad efectiva que la gestión le atribuyó al deudor y del mantenimiento de la aequitas entre las partes de la obligación ${ }^{118}$.

113 En efecto, observa EsCala (1935), ([S.I.], v. 1, n. 1-2. Ene.): "Como puede verse, la contradicción es evidente: el artículo 1574 niega acción al que paga contra la voluntad del deudor, en todo caso; el 2291, se la concede cuando el pago le haya sido útil y subsistiere esa utilidad al tiempo de la demanda". Menciona como una "notoria contradicción" también Ospina (2014), p. 325 y SerRano (2011), p. 194.

114 Claro (1979), p. 52, nt. 30.

115 En efecto, señala Claro (1979), p. 52, nt. 30: "A primera vista parece que hubiera contradicción entre los arts. 1574 y 2291 [...] pero como puede haber beneficiado efectivamente al deudor, quien a pesar de las razones invocadas por él para no pagar, hubiera debido pagar, con lo que se ha hecho más rico, existe la acción de in rem verso para demandar aquello en que ese pago le ha sido realmente útil, que es la acción del art. 2291 y que puede ser inferior a lo efectivamente pagado por el tercero".

116 A la base de este razonamiento estaría la teoría prospectada por Juliano en D. 46,1,17, respecto a entender la cesión de las acciones de crédito como una venta de dichas acciones, para que de tal modo no se extingan a causa de la solutio, confróntese Briguglio (1999), pp. 267 y ss.; Provera (1983), pp. 639 y ss.

117 Esta tendencia encuentra sustento sobre la base del criterio que permite dar relevancia a la gestión a pesar de la prohibición del interesado, y que se basa en que sin la intervención prohibida se incumpliría una obligación de interés público, confróntese SánCHEZ (2000), p. 290. A tal respecto, observa WINDSCHEID (1904), p. 273: «[...] ogni ragione di risarcimento bien meno, se il gestore dell'affare ha fatto il sacrificio contro un divieto del dominus; alla qual'ultima massima v'è però una eccezione nel caso, in cui alcuno ha invece dell'obbligato seppelito un defunto».

118 Lo cual tiene como fundamento el razonamiento del Pothier, quien criticó a D. 17,1,40, dando relevancia al restablecimiento de la aequitas quebrantada a causa del injusto enriquecimiento obtenido por el deudor. 
Por otra parte, para Abeliuk Manasevich ${ }^{119}$ resulta más equitativa dicha disposición, ya que ampara un injusto enriquecimiento para el deudor, "que se economiza el pago sin dar nada a cambio"120.

Por lo que se refiere al instrumento procesal admitido por la doctrina ${ }^{121}$ para actuar el regreso, se considera que, al haberse hecho más rico el que debía pagar su deuda, el solvens dispondrá de la acción de rem in verso para demandar la parte del pago que le hubiere sido de utilidad al deudor; por lo que cabe el rembolso, pero en un monto inferior a lo que efectivamente pagó el solvens ${ }^{122}$.

Sin embargo, esta tendencia ha encontrado críticas por parte de la doctrina moderna, como la de Ospina Fernández, quien considera que la tendencia a admitir el derecho de regreso carece de toda justificación jurídica ${ }^{123}$.

Y del mismo parecer es Figueroa Vásquez, quien considera que se debe rechazar la acción de enriquecimiento a causa de la conducta temeraria del tercero solvens ${ }^{124}$.

En este sentido, la problemática concerniente al derecho de regreso para el solvens prohibente debitore ha instaurado nuevamente un debate doctrinal igual al que se verificó a lo largo del iter histórico del sistema jurídico romanista.

No obstante, es evidente que el elemento de la utilidad efectiva para el deudor, consecuencia de la intervención del tercero solvens, está a fundamento

\footnotetext{
119 Abeliuk ManaseVich (2001), pp. 551 y 597.

120 Así Abeliuk (2001), p. 551. De su parte, Meza (2014), p. 169, se limita a interrogarse cómo solucionar dicha controversia, exponiendo las teorías de dos autores chilenos: "Don Leopoldo Urrutia piensa que la regla del art. 2291 es aplicable cuando el pago es útil al deudor, mientras que si no lo es será aplicable la norma del art. 1574. No sería útil el pago a un acreedor benévolo, en tanto que el tercero que paga se propone ejecutar al deudor. Sería útil al deudor el pago que evita una acción judicial" y "Para don Ruperto Bahamontes, el art. 1574 es aplicable cuando se trata de pagos aislados; el art. 2291 lo es, en cambio, cuando el pago es parte de un conjunto de actos de administración de un negocio ajeno".

121 Claro (1979), p. 52, nt. 30; Meza (2014), p. 169.

122 Es decir, sin contar los intereses, gastos y demás perjuicios, véase SerRano (2011), p. 196.

${ }^{123}$ En efecto, observa Ospina (2014), p. 326: "Repugna a la lógica [...] que se permita a un extraño autoerigirse en árbitro de la utilidad que tales derechos reporten a sus titulares y a inmiscuirse en su guarda, aun contra el querer de ellos. Y todavía se justifica menos reconocerle al agente oficioso que obra contra la prohibición del dueño del negocio, derecho alguno contra este [...]. Y todavía es más aberrante que, en tales circunstancias, se le otorgue a ese tercero una acción de reembolso contra mí".

124 Señala Figueroa (1997), p. 158: "cada vez que el empobrecido actúa contra la voluntad expresa del enriquecido, obra por ello negligentemente, y se debe rechazar la acción de enriquecimiento sin causa dada la gravedad de su conducta".
} 
de la admisión del derecho de regreso establecido en el artículo 2291; esta utilidad se relaciona con el restablecimiento de la equidad natural, y por consecuencia, está dirigida a evitar que el deudor se enriquezca de manera injustificada.

\section{Conclusiones}

Del presente estudio, podemos concluir que el alcance de la romana actio utilis en el Código Civil de Bello para el supuesto prohibente debitore, se manifestó en el mantenimiento de la aequitas entre las partes de la obligación y, por consiguiente, en la necesidad de evitar un enriquecimiento injustificado para el deudor liberado.

Así, por una parte, esta actio utilis habría tenido la función de extender el campo de aplicación de una acción preexistente a nuevas hipótesis no previstas, con el fin de restablecer el equilibrio perdido, el mismo que, para el supuesto prohibente debitore, se identificaba en la ficción de que el deudor jamás había prohibido la intervención del tercero en su esfera patrimonial y, de esta forma, admitir el derecho de regreso mediante la adaptación de la actio negotiorum gestorum en vía útil.

Esta posición resulta ser la tesis que, desde los glosadores medievales, ha asumido una parte de la doctrina romanística que se ha pronunciado sobre el tema, a pesar de algunas posturas doctrinales contrarias y de la posible incompatibilidad de ciertos institutos reconocidos por la dogmática jurídica moderna. En efecto, surge el problema de la adaptación de la actio (in factum) negotiorum gestorum en vía útil como acción ficticia, ya que las actiones in factum estaban dirigidas a suplir un elemento de hecho y no un elemento o cualidad jurídica, situación esta última en la que cabría identificar a la actio utilis como acción ficticia.

No obstante, estos fundamentos romanistas habrían sido tomados en consideración a lo largo de la historia jurídica europea, en particular, por la doctrina civilista francesa que influenciaría el movimiento codificador en Latinoamérica. Así, la normativa del Código Civil de Bello concerniente a la admisión del derecho de regreso para el solvens prohibente debitore establecida en el artículo 2291, considera a la utilidad efectiva que obtuvo el deudor como el fundamento del reembolso en favor del solvens y así evitar un desequilibrio patrimonial entre las partes.

Por otra parte, hay que considerar también la tesis que identifica a la actio utilis con aquella acción que era cedida por el acreedor satisfecho en favor del tercero solvens al objeto de que pueda dirigirse en contra del deudor principal. Esta circunstancia, prevista desde el Derecho Romano clásico, podría haber influenciado la redacción del artículo 1574, el mismo que deja abierta 
la posibilidad de actuar el reembolso en favor del solvens, pero condicionada a la cesión que, de forma voluntaria, le haría el acreedor de sus acciones.

Sin embargo, la reglamentación del Código de Bello no supo dar una solución clara al problema y, más bien, determinó una contradicción entre las normas que regulan el pago prohibente debitore. En efecto, a pesar de que el referido artículo 1574 admite al final la posibilidad de recurrir a la subrogación convencional, la norma no establece ipso iure el reembolso en favor del solvens, determinando, por consecuencia, el surgimiento de la contradicción con el artículo 2291, que en cambio admite explícitamente el derecho de regreso en favor del solvens.

Así pues, a través de la presente investigación se han dado a conocer los fundamentos romanistas de la contradicción existente en el Código Civil de Bello sobre el derecho de regreso consiguiente al pago del tercero prohibente debitore, y las posibles soluciones prospectadas por la doctrina, lo que podrá contribuir a consolidar una postura sobre esta problemática, la misma que ha sido históricamente debatida a lo largo de nuestro sistema jurídico romanista.

\section{BiBLIOGRAFÍA CITADA}

Abeliuk Manasevich, René (2001): Las obligaciones, $4^{\text {a }}$ edición (Santiago, Editorial Jurídica de Chile), Tomo II.

Albiez Dohrmann, Klaus Jochen (1996): "El pago por tercero", en: Cuadernos de Derecho Judicial (№ 26), pp. 13-88.

Alonso Pérez, Mariano (2007): "Doscientos años del Code civil des français en USC (1804-2004). Catálogo de la exposición celebrada en la Biblioteca Concepción Arenal de la Universidad de Santiago de Compostela, 2005", en: Anuario de Derecho Civil (t. LX, fasc. II), pp. 849-892.

AtZerI, Francesco (1898): I requisiti essenziali della negotiorum gestio. (Parte teorico-pratica). Studio comparato di diritto romano-civile-commerciale (Cagliari, s.e), Vol. I.

Atzerl, Francesco (1904): La gestione d'affari altrui nella dottrina e nella giurisprudenza (Torino, s.e).

Astutı, Guido (1958): "'Arricchimento' (azione di) (Premessa storica)", en: Enciclopedia del Diritto ( $\left.N^{\circ} 3\right)$, pp. 52-63.

Baviera, Giovanni (1898): Le due scuole dei giuriconsulti romani (Firenze, "L'Erma" di Bretschneider-ed. Anastatica Roma 1970).

Bayo Recuero, Nieves (2000): El pago del tercero. Subrogación (Madrid, Dijusa). 
Bello, Andrés (1888): Proyecto de Código Civil (1853), Obras completas de Don Andrés Bello, Edición hecha bajo la dirección del Consejo de Instrucción Pública en cumplimiento de la lei de 5 de septiembre de 1872 (Santiago de Chile), Vol. XII.

Bello, Andrés (1981): Derecho Romano, Obras Completas de Andrés Bello (Caracas, La Casa de Bello), Vol. XVII.

BellonI, Annalisa (1989): "Le questioni civilistiche del secolo XII: da Bulgaro a Pillio da Medicina e Azzone", en: Ius Commune, Sonderhefte: Studien zur europäischen Rechtsgeschichte (Vol. 43), p. 452.

Berger, Adolf (1953): (voz) "Actiones directae", en: Encyclopedic dictionary of roman law (Vol. 43, part. 2), pp. 345-346.

Berger, Adolf (1953): (voz) "Actiones utiles", en: Encyclopedic dictionary of roman law (Vol. 43, part. 2), p. 347.

Berger, Adolf (1953): (voz) "Actiones vulgares", en: Encyclopedic dictionary of roman law (Vol. 43, part. 2), p. 348.

Bernad SegarRa, Lucía (1999): Relaciones entre fianza y mandato en el derecho romano (Alicante, Club universitario).

Betancourt Serna, Fernando (1980): "Sobre las 'exceptiones' llamadas 'utiles'", en: Anuario de Historia del Derecho Español ( N ${ }^{\circ} 50$ ), pp. 699-719.

BIANCHI, Ernesto (1997): Fictio iuris. Ricerche sulla finzione in diritto romano dal periodo arcaico all'epoca augustea (Padova, Cedam).

Bıond, Biondo (1972): Istituzioni di diritto romano, $4^{\text {a }}$ ed. (Milano, s.e.).

Bortoluccl, Giovanni (1909): Actio utilis (Modena, Società tipografica modenese).

Briguglio, Filippo (1999): Fideussoribus succurri solet (Milano, Giuffrè).

BuONAMICI, Francesco (1886): La storia della procedura civile romana (Pisa, ed. anast. Roma, 1971. L'Erma di Bretschneider), Vol. I.

Cannata, Carlo Augusto (1982): Profilo istituzionale del processo privato romano. II: Il processo formulare (Torino, Giappichelli).

Cannata, Carlo Augusto (2005): "Cum alterius detrimento et iniuria fieri locupletiorem L'arricchimento ingiustificato nel diritto romano", en: A.A. V.V., Arricchimento ingiustificato e ripetizione dell'indebito. VI Convegno internazionale ARISTEC, Padova-Verona-Padova, 25-26-27 settembre 2003 (Padova- Verona, ed. L. Vacca), pp. 13-50.

Cardilli, Riccardo (2004): «Bona fides» tra storia e sistema. Studi su origine ed attualità del sistema romano (Torino, Giappichelli), Tomo 3. 
CAVAllaro, Rosaria (2001): La gestione d'affari altrui prohibente domino neIla tradizione romanistica (Milano, Pubblicazioni dell'I.S.U. Università Cattolica).

Cenderelu, Aldo (1997): La negotiorum gestio. Corso esegetico di diritto romano (Torino, Giappichelli).

Cenderelli, Aldo (1999): "Actio negotiorum gestorum directa e contraria nel linguaggio romano classico e giustinianeo", en: A.A. V.V. Règle et pratique du droit dans les réalités juridiques de l'antiquité. Atti de la Société Internationale Fernand De Visscher pour l'Historie des Droits de l'Antiquité. Atti della 51 a Sessione (Crotone-Messina, 16-20/9/1997) (ed. I. Piro), pp. 289-298.

Claro Solar, Luis (1979): Explicaciones de derecho civil chileno y comparado. De las obligaciones, (Santiago, Editorial Jurídica chilena), Tomo IV.

Coglıolo, Pietro (1890): Trattato teorico pratico della amministrazione degli affari altrui nel diritto civile, commerciale e marittimo (Firenze, s.e.), Vol. II.

CRUz, Sebastiäo (1962): Da 'Solutio'; terminología, conceito e características, e análise de vários institutos afins. I. Epocas arcaica e classica (Coimbra, Livraria Almedina).

Del Olmo García, Pedro (1998): Pago de tercero y subrogación (Madrid, Civitas).

Díaz de Entre Sotos Forns, María (1990): "El aprovechamiento de las ventajas de la gestión de negocios y sus consecuencias jurídicas", en: Revista de la Facultad de Derecho de la Universidad Complutense ( $\left.N^{\circ} 75,1989-90\right)$, pp. 157-196.

Dı́́z-PıCAZO, Luis (2011): "La doctrina del enriquecimiento injustificado", en: Ensayos Jurídicos (1953-2011). Tomo II: Derecho de obligaciones y contratos. Derecho de daños. Enriquecimiento injustificado, (Madrid, Thomson Reuters-Civitas), pp. 3029-3115.

D'Ors, Álvaro (2004): Derecho privado romano (Pamplona, Eunsa).

Duranton, Alexandre (1841): Cours de droit civil, suivant le Code français avec des sommaires ou exposés analytiques en tête de chaque chapitre et section de matière, $4^{\mathrm{a}}$ ed. (Bruxelles, s.e.), Tomo VII.

EmUnDS, Christian (2007): Solvendo quisque pro alio liberat eum. Studien zur befreienden Drittleistung im klassischen römischen Recht (Berlín, Dunker \& Humblot).

Escala, Enrique (1935): "Bello y el Código Civil chileno. Comentarios acerca de la obra Don Andrés Bello, de Eugenio Orrego Vicuña", en: Anales de la Facultad de Ciencias Jurídicas y Sociales ([S.I.], v. 1, n. 1-2. Ene). 
Disponible en: http://www.analesderecho.uchile.cl/index.php/ACJYS/article/view/3987/3883 [Visitado el 20/7/2017].

FALCHI, Gian Luigi (1981): Le controversie tra Sabiniani e Proculeiani (Milano Giuffrè).

FarGnOL, Iole (2008): "Ch. Emunds, Solvendo quisque pro alio liberat eum. Studien zur befreienden Drittleistung im klassischen römischen Recht, Berlin, 2007", en: Studia et Documenta Historia et luris (№ 74), pp. 886-896.

Finazzl, Giovanni (1999): Ricerche in tema di negotiorum gestio. I. Azione pretoria e azione civile (Napoli, Jovene Editore).

FINAZZI, Giovanni (2003): Ricerche in tema di negotiorum gestio, II/1, Requisiti delle actiones negotiorum gestorum (Napoli, Collana di Ateneo dell'Università degli Studi di Cassino).

FinazZI, Giovanni (2006): Ricerche in tema di negotiorum gestio. II/2. Obbligazioni gravant sul gestore e sul gerito e responsabilità (Napoli, Collana di Ateneo dell'Università degli Studi di Cassino).

Fernández BarReiro, Alejandrino (1971): "Procedimientos técnicos para la creación jurisprudencial del Derecho en Roma", en: Anuario de Historia del Derecho Español (XLI, V), pp. 713-722.

FERNÁNDEZ VILLA, José Ángel (1999): El pago con subrogación: revisión del artículo 1212 del Código Civil español (Granada, Comares).

Figueroa Vásquez, Waldo Enrique (1997): La acción de enriquecimiento sin causa (Santiago de Chile, Editorial Jurídica ConoSur).

FrezZA, Paolo (1962): Le garanzie delle obbligazioni. Corso di diritto romano. I. Le garanzie personali (Padova, Cedam).

García del Corral, Idelfonso (1889): Cuerpo del Derecho civil romano (Barcelona, ed. facsímil 1988 Valladolid).

García Garrido, Manuel Jesús (1957-1958): "Sobre los verdaderos límites de la ficción en Derecho Romano", en: Anuario de Historia del Derecho Español (XXVII-XXVIII), pp. 305-342.

GIRARD, Paul Frédéric (1909): Manuale elementare di diritto romano, $4^{a}$ edición (traducc. Carlo Longo, Milano, Società Editrice Libraria).

GLÜCK, Christian Friedrich von (1888): Commentario alle Pandette, III, (traducc. Contardo Ferrini, Milano Società editrice libraria).

Guarino, Antonio (2001): Diritto privato romano, $12^{\mathrm{a}}$ ed. (Napoli, Jovene editore).

GuZmán Brito, Alejandro (1978): "Sobre el objeto de las ficciones pretorias", en: Revista Chilena de Historia del Derecho ( $\left.N^{\circ} 7\right)$, pp. 9-19. 
GuZmÁn Brito, Alejandro (1996): Derecho privado romano (Santiago, Editorial Jurídica de Chile), Tomo II.

GuZMÁn Brito (2000): La codificación civil en Ibero América. S. XIX y XX (Santiago, Editorial Jurídica de Chile).

Guzmán Brito (2006): "El Código Civil de Chile en sus ciento cincuenta años y crónica de un congreso internacional de conmemoración celebrado en Santiago de Chile", en: Anuario de Derecho Civil (N 3), pp. 1283-1301.

Hallebeek, Jan (1995): "Developments in Medieval Roman Law", en: A.A. V.V., Unjust Enrichment. The Comparative Legal History of the Law of Restitution (Comparative Studies in Continental and Anglo-American Legal History, 15) (Berlín, ed. E.J.H. Schrage), pp. 59-120.

HÄNEL, Gustav (1834): "Dissensiones dominorum sive controversiae veterum iuris romani interpretum qui glossatores vocantur" (Lipsiae, s.e).

KUPISCH, Berthold (1994): (voz) "Arricchimento nel diritto romano, medievale e moderno", en: Digesto delle discipline privatistiche. Sezione civile $\left(\mathrm{N}^{\circ} 1\right)$, pp. 423-446.

LASTARRIA, José Victorino (1864): Instituta del derecho civil chileno, $2^{\mathrm{a}}$ edición (Gante, Imprenta de Eug. Vanderhaeghen).

Lenel, Otto (1889): Palingenesia iuris civilis (Leipzig. Ex officina Bernhardi Tauchnitz), Vol. I.

Lenel, Otto (1927): Das edictum perpetuum (Leipzig. Ex officina Bernhardi Tauchnitz), Vol. II.

Levy, Ernestus y RABEL, Ernestus (1935): Index interpolationum (Weimar, Böhlau), Vol. I.

Llambías, Jorge Joaquín (1993): Tratado de derecho civil. Obligaciones. Transmisión de las obligaciones, extinción de las obligaciones, pago (Buenos Aires, Editorial Abeledo Perrot), Tomo II B.

LuIG, Klaus (2005): "Il divieto d'arricchimento e la volontà dell'arricchito nel Usus modernus", en: A.A. V.V., Arricchimento ingiustificato e ripetizione dell'indebito. VI Convegno Internazionale ARISTEC, Padova-VeronaPadova, 25-26-27 settembre 2003 (Torino, ed. L. Vacca), pp. 53-71.

Luzzatto, Giuseppe Ignazio (1969): “H. H. SeILER, Der Tatbestand der negotiorum gestio im römischen Recht, Köln, 1968", en: Studia et Documenta Historia et luris ( $\left.\mathrm{N}^{\circ} 35\right)$, pp. 479-489.

Mantovani, Dario (1999): Le formule del processo privato romano. Per la didattica delle istitutzioni di diritto romano (Como, Edizioni New Press). 
Mercoglano, Felice (2001): «Actiones ficticiae». Tipologie e datazione, 48 (Napoli, Jovene Editore).

Meza Barros, Ramón (2014): Manual de Derecho Civil. De las obligaciones, $10^{a}$ edición (Santiago, Editorial Jurídica de Chile).

NicosiA, Giovanni (1969): (voz) "Gestione d'affari altrui (Premessa storica)", en: Enciclopedia del Diritto ( $\left.{ }^{\circ} 18\right)$, pp. 628-643.

Ospina Fernández, Guillermo (2014): Régimen general de las obligaciones, $8^{\text {a }}$ edición (Bogotá, Temis).

PACCHIONI, Giovanni (1893): Trattato della gestione degli affari altrui secondo il diritto romano e civile (Lanciano, Rocco Carabba).

PACCHIONI, Giovanni (1935): Della gestione degli affari altrui secondo il diritto romano, civile e commerciale, $3^{\text {a }}$ edición (Padova, Cedam).

PACCHIONI, Giovanni (1935): Manuale di diritto romano, $3^{\text {a }}$ edición (Torino, Utet).

Pasquau Liaño, Miguel (1986): La gestión de negocios ajenos (Madrid, Montecorvo).

Pili Medicinensis (1967): "Quaestiones Sabbatinae", en: Corpus Glossatorum iuris civilis (Torino, Romae. rist.), Tomo IV.

PothieR, Robert Joseph (1824): "Appendice au Traité du quasi-contrat de negotiorum gestorum", en: Oeuvres de Pothier, contenat les traités du droit français (Paris, Béchet Ainé, Libraire), Tomo IV.

Pothier, Robert Joseph (1939): Tratado de las obligaciones (traducc. S.A.C. Barcelona), Tomo I.

Prado Rodríguez, Juan Carlos (2009): "Reconstrucción de una disputa jurisprudencial romana sobre el derecho de regreso consiguiente a la negotiorum gestio prohibente domino", en: Revista General de Derecho Romano - lustel (No 12), pp. 1-31.

Provera, Giuseppe (1983): "Riflessioni sul beneficium cedendarum actionum", en: Studi Sanfilippo IV, pp. 609-659.

Riccobono, Salvatore (1906): "Tracce di diritto romano classico", en: Bulletino dell'Istituto di Diritto Romano (No 18), pp. 197-222.

Riccobono, Salvatore (1915): Dal diritto romano classico al diritto moderno (Palermo, L. Gaipa).

Riccobono, Salvatore (1917): "La gestione d'affari altrui e I'azione d'arricchimento nel diritto moderno", en: Rivista di Diritto Commerciale (Año XV, No 5-6), pp. 1 y ss. 
Riccobono, Salvatore (1937): (voz) "Aequitas", en: Nuovissimo Digesto Italiano (No 1), pp. 210-215.

RIPOSATI, Benedetto (1965): "Una singolare nozione di aequitas in Cicerone", en: Studi in onore di B. Biondi, II, pp. 447-465.

Rivalta, Valentino (1895): Dispute celebri di diritto civile (Bologna, Zanichelli). RodríGuez EnNes, Luis (2012): "La permanencia del derecho romano en los códigos europeos e iberoamericanos", en: Anuario de la Facultad de Dereito da Universidade da Coruña ( $\left.N^{\circ} 16\right)$, pp. 737-755.

SALAS, Acdeel (1982): Obligaciones, contratos y otros ensayos (ed. póstuma) (Buenos Aires, Depalma).

SÁnCHEZ JordÁn, María Elena (2000): La gestión de negocios ajenos (Madrid, Civitas).

SCHIPANI, Sandro (2007): Iustiniani augusti digesta seu pandectae. Testo e traduzione. 12-19 (Milano, Giuffrè), Tomo III.

SCiAloja, Vittorio (1889): "Della negotiorum gestio prohibente domino ed in ispecie dell'azione di regresso del terzo che paghi un debito altrui contro la volontà del debitore", en: Foro Italiano (Año XIV, fascículo XVI), pp. 1-32.

SCIAloja, Vittorio (1894): Esercizio e difesa dei diritti (Roma,Tipografía Fratelli Pallotta).

Schulz, Fritz (1930): "Nachklassiche Questionen in den justinianischen Reformgesetzen des Codex Justinianus", en: Zeitschrift der Savigny-Stiftung für Rechtsgeschichte: Romanistische Abteilung ( ${ }^{\circ}$ 50), pp. 212-248.

SCHINDLER, Karl Heinz (1966): Justinians Haltung zur klassik (Köln-Graz, Böhlau Verlag).

SEILER, Hans Hermann (1968): Der Tatbestand der negotiorum gestio in römischen Recht (Köln, Böhlau).

SerRAO, Feliciano (1947): Il procurator (Milano, Giuffrè).

Serrano Herrera, Claudia (2011): "La legitimación para el pago de un tercero", en: Revista de Derecho de la Pontifica Universidad Católica de Valparaíso ( No XXXVII), pp. 137-211.

SiLlA, Francesco Maria (2007): "Il rimborso delle spese funerarie in caso di prohibitio heredis. Ulp. 25 ad edictum D. 11,7,14,13", en: A.A. V.V., Testi e problemi del giusnaturalismo romano (ed. D. Mantovani-A. Schiavone. Collegio di Diritto Romano 2005) (Pavia, Cedant), pp. 645-674.

Solazzı, Sirio (1935): L'estinzione dell'obbligazione nel diritto romano, $2^{\text {a }}$ edición (Napoli, Jovene). 
SOTTY, Richard (1977): Recherche sur les utiles actiones. La notion d'action utile en droit romain classique (Grenoble, Service de reproduction des theses de L'université des sciences sociales de Grenoble).

Sotтr, Richard (1979): "Les actions qualifées s'utiles en droit classique", en: Labeo (No 25), pp. 152-162.

Stoljar, Samuel (2007): "Negotiorum gestio", en: Von Caemmerer, Ernst (editor), International Encyclopedia of Comparative Law, X. Restitution/Unjust Enrichment and negotiorum gestio (ed. E.V. Caemmerer-P. Schlechtriem) (Leide-Boston, Martinus Nijhoff Publishers), pp. 3-105.

Talamanca, Mario (1968): (voz) "Fideiussione (Parte storica)", en: Enciclopedia del Diritto (No XVII), pp. 322-343.

Talamanca, Mario (1987): (voz) "Processo civile (Diritto romano)", en: Enciclopedia del Diritto ( ${ }^{\circ} \mathrm{XXXVI)}$, pp. 1-72.

Talamanca, Mario (2001): Elementi di diritto romano privato (Milano, Giuffrè).

TOULlier, Charles Bonaventure Marie (1830): Le droit civil français, $6^{\text {a }}$ edición (Paris), Vol. IV.

Troplong, Raymond-Theodore (1846): Le droit civil expliqué suivant I'ordre du code. Du mandat, du cautionnement et des trasactions (Bruxelles, Société typographique belge).

Tur Faúndez, María Nélida (1996): El derecho de reembolso. En el pago por tercero, regímenes económico-matrimoniales, solidaridad, fianza, responsabilidad civil y otros supuestos (Valencia, Editorial General de Derecho).

TurCo, Claudio (2002): L'adempimento del terzo (Milano, Giuffrè).

Valiño, Emilio (1974): Actiones utiles (Pamplona, Ediciones Universidad de Navarra).

VéLEZ, Fernando (1926): Estudio sobre el derecho civil colombiano, 2a edición (París, París-América), Tomo VI.

Vigneron, Roger (1974): "Fideiussor, qui pecuniam deposuit, confestim agere mandati potest", en: Bulletino dell'Istituto di Diritto Romano (Año 16, No LXXVII), pp. 443-494.

WindsCheiD, Bernanrd (1904): Diritto delle pandette (traducc. Fadda-Bensa. Torino, Utet), Vol. II

Zachariae, Karl Salomon (1867): Corso di diritto civile francese, $2^{\text {a }}$ edición (traducc. F. Fulvio, Napoli, s.e.), Tomo I.

Zimmermann, Reinhard (1990): The law of obligations. Roman foundations of the civilitian tradition (Cape Town, Juta\&Co.). 
NORMAS JURÍDICAS CITADAS

Proyecto de Código Civil chileno de 1853.

Art. 1755.

Art. 2443 a.

Código Civil chileno (1855).

Art. 1572.

Art. 1573.

Art. 1574.

Art. 1610

Art. 1611.

Art. 2291.

Art. 2345.

Art. 2370 .

Art. 2375.

Código Civil argentino (1869).

Art. 728. 